\title{
How Fast Can China Grow? The Middle Kingdom's Prospects to 2030
}

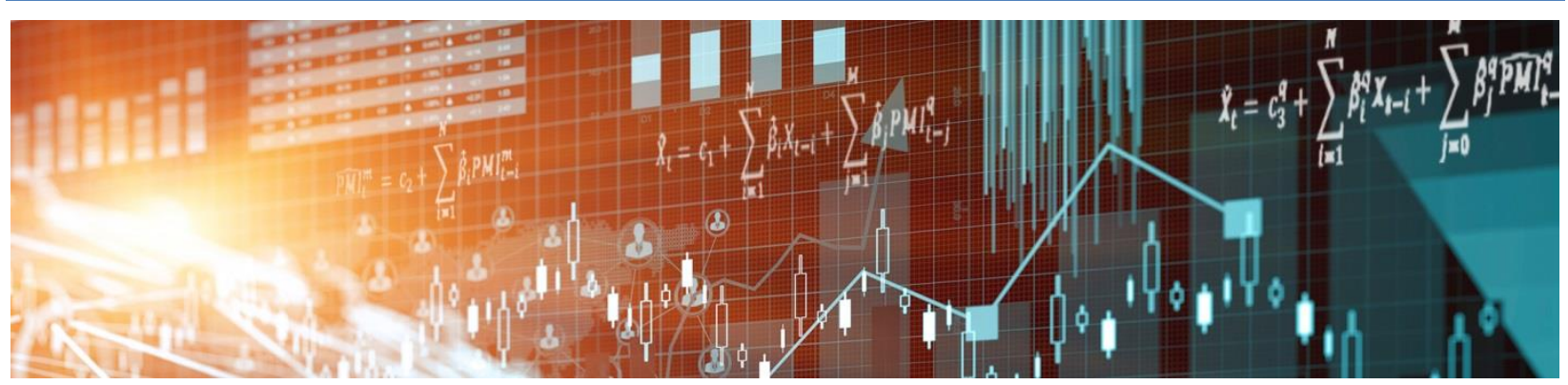

by Jeannine Bailliu, Mark Kruger, Argyn Toktamyssov and Wheaton Welbourn 
Bank of Canada Staff Working Paper 2016-15

April 2016

\section{How Fast Can China Grow? The Middle Kingdom's Prospects to 2030}

by

Jeannine Bailliu, Mark Kruger, Argyn Toktamyssov and Wheaton Welbourn

International Economic Analysis Department

Bank of Canada

Ottawa, Ontario, Canada K1A 0G9

Corresponding author: jbailliu@bankofcanada.ca 


\section{Acknowledgements}

The authors would like to thank Oleksiy Kryvtsov and James Yetman for their comments, as well as participants at the HKIMR's Annual International Conference on the Chinese Economy, the Annual Meetings of the Canadian Economic Association, a CEANA session at the Allied Social Sciences Association Meeting, and at seminars at the Bank of Canada, the European Central Bank, and the Banque de France. They also thank Nicholas Ellery and Nadine Abouseif for their excellent research assistance. 


\begin{abstract}
Given its size and importance for global commodity markets, the question of how fast the Chinese economy can grow over the medium term is an important one. This paper addresses this question by examining the evolution of the supply side of the Chinese economy over history and projecting how it will evolve over the next 15 years. Using a Cobb-Douglas production function, we decompose the growth of trend GDP into those of the capital stock, labour, human capital and total factor productivity (TFP) and then forecast trend output growth out to 2030 using a bottom-up approach based on forecasts that we build for each one of these factors. Our paper distinguishes itself from existing work in that we construct a forecast of Chinese TFP growth based on the aggregation of forecasts of its key determinants. Moreover, our analysis is based on a carefully constructed estimate of the Chinese productive capital stock and a measure of human capital - based on Chinese wage survey data - that better reflects the returns to education in China. Our results suggest that Chinese trend output growth will decelerate from around $7 \%$ currently to about $5 \%$ by 2030 , and are consistent with a gradual rebalancing of the Chinese economy characterized by a decline in the investment rate.
\end{abstract}

JEL classification: 04, E32, E22, E23

Bank classification: Development economics; International topics; Potential output; Productivity

\title{
Résumé
}

Compte tenu de la taille de l'économie chinoise et de l'importance de celle-ci pour les marchés mondiaux des produits de base, il est pertinent de s'interroger sur le rythme de croissance potentiel de cette économie à moyen terme. Nous nous prêtons à l'exercice en étudiant l'évolution de l'offre dans le temps au sein de l'économie chinoise et en anticipant la progression de cette dernière dans les 15 années à venir. À l'aide d'une fonction de production Cobb-Douglas, nous décomposons la croissance tendancielle du PIB en quatre facteurs - l'accroissement du stock de capital, la hausse de la maind'œuvre, l'augmentation du capital humain et l'amélioration de la productivité totale des facteurs (PTF) -, puis prévoyons la croissance tendancielle de la production jusqu'en 2030 à l'aide d'une approche ascendante fondée sur nos prévisions pour chacun de ces facteurs. Notre article se distingue des travaux actuels en ce que nous construisons une prévision de la croissance de la PTF chinoise à partir de l'agrégation de prévisions concernant ses principaux déterminants. Par ailleurs, notre analyse repose sur une estimation rigoureusement construite du stock de capital productif en Chine et sur une mesure du capital humain - d'après des données d'enquête sur les salaires chinois - qui 
tient mieux compte des rendements de l'éducation dans ce pays. Nos résultats donnent à penser que la croissance tendancielle de la production chinoise ralentira pour passer d'environ $7 \%$ actuellement à $5 \%$ d'ici 2030, et cadrent avec un rééquilibrage progressif de l'économie chinoise, marqué par une baisse du taux d'investissement.

Classification JEL : 04, E32, E22, E23

Classification de la Banque : Économie du développement; Questions internationales;

Production potentielle; Productivité 


\section{Non-Technical Summary}

Although the Chinese economy is expected to moderate going forward, there is no clear consensus regarding the extent and pace of the anticipated slowdown. Given its size and importance for global commodity markets, the question of how fast China can grow over the medium term is an important one. This paper addresses this question by looking at the evolution of the supply side of the Chinese economy over history and projecting how it will evolve over the next 15 years. Using a Cobb-Douglas production function, we decompose the growth of trend GDP into those of the capital stock, labour, human capital and total factor productivity (TFP) and then forecast trend output growth out to 2030 using a bottom-up approach based on forecasts that we construct for each one of these factors.

In contrast to the literature that examines China's rapid growth over history, our paper focuses on how fast it is likely to grow going forward. It distinguishes itself from existing empirical work on forecasting Chinese growth along three main dimensions. First, we draw on the literature on the determinants of TFP growth to construct a forecast of Chinese TFP growth based on the aggregation of forecasts of its key factors. As China slows, TFP growth will become an increasingly important determinant of trend GDP growth. Therefore, understanding the drivers of its TFP growth is key to assessing how, and how fast, China will grow.

Second, our analysis uses a measure of human capital - based on Chinese wage survey data - that better reflects past and anticipated returns to education in China. Finally, our analysis is based on a carefully constructed estimate of the Chinese productive capital stock that excludes housing. Housing should not be included in a measure of the capital stock when capital is defined as an input used to produce goods and services, as it is in this context. However, in contrast to our paper, Chinese growth studies based on a CobbDouglas production function framework tend to use capital stock measures that include housing.

Our results suggest that Chinese trend output growth will decline gradually from about $7 \%$ currently to just above $5 \%$ by 2030 , driven mostly by a slowdown in capital accumulation. Forecast comparisons with other studies suggest that our results are broadly in line with the literature in that most studies forecast a decline in trend output growth, driven by a reduction in capital stock growth.

Our findings can be used to gain some insights into whether, and to what extent, the Chinese economy is expected to rebalance over the next decade and a half. Our forecasting results are consistent with a gradual rebalancing of the Chinese economy characterized by a decline in the investment rate from close to $50 \%$ currently to around $25 \%$ by 2030 . However, these results are implicitly contingent on the implementation of productivityenhancing reforms that support robust TFP growth. 


\section{Introduction}

There is considerable uncertainty regarding the pace at which the Chinese economy can grow

over the medium term. Studies such as those by the World Bank $(2015,2013)$ and OECD (2014) are fairly bullish on China's prospects. They project growth to 2030 averaging 5-6\%. While this would represent a significant slowdown in growth experienced since the beginning of reforms in the late 1970s, it is still quite robust, especially for a country as large as China.

In contrast, a number of papers have been written which warn that China faces the risk of an abrupt slowdown in the near future. These bearish analyses fall into two broad groups: those that draw on the growth experience of a wide variety of countries and those that emphasize China-specific factors.

In the first group, Eichengreen et al. (2012) examine a sample of cases of fast-growing countries, whose growth slowed significantly. These slowdowns typically come about through a sharp fall in total factor productivity (TFP) growth as a point is reached in the growth process where it is no longer possible to boost productivity growth by shifting additional workers from agriculture to industry and where the gains from importing foreign technology diminish. Drawing on this analysis, Eichengreen et al. (2012) project that China will slow significantly in the 2015-2017 period. In a similar vein, Pritchett \& Summers (2014) note that developing country growth rates are strongly episodic and large (4 percentage point) shifts in medium-term growth rates are common. They believe that, based on the experience of other countries' growth rates regressing to the mean, continued rapid growth in China is unlikely.

In the second group, there are those such as Dollar \& Wei (2014) and Lee et al. (2013) who show that China's investment-led growth model has been wasteful and that investment has been excessive. Guo \& N'Diaye (2014) take exception to the sustainability of the export orientation of China's growth. Their research shows that maintaining the export-oriented growth model would require significant gains in China's market share. However, their reading of the experience of other Asian economies that had similar export-oriented growth suggests there are limits to the global market share that a country can occupy. Wang (2012) describes the sharp demographic transition through which China will go and how the cost of labour will rise, savings will fall and government revenue will decline.

Given the size of the Chinese economy and its importance for global commodity markets, the question of how fast China can grow over the medium term is an important one. This paper addresses this question by looking at the evolution of the supply side of the Chinese 
economy over history and projecting how it will evolve over the next 15 years. Using a Cobb-Douglas production function, we decompose the growth of trend GDP into those of the capital stock, labour, human capital and total factor productivity (TFP) and then forecast trend output growth out to 2030 using a bottom-up approach based on forecasts that we construct for each one of these factors.

In contrast to the literature that examines China's rapid growth over history, our paper focuses on how fast it is likely to grow going forward. ${ }^{1}$ It distinguishes itself from existing empirical work on forecasting Chinese growth along three main dimensions. First, we draw on the literature on the determinants of TFP growth to construct a forecast of Chinese TFP growth based on the aggregation of forecasts of its key factors. As China slows, TFP growth will become an increasingly important determinant of trend GDP growth. Therefore, understanding the drivers of its TFP growth is key to assessing how, and how fast, China will grow.

Second, our analysis uses a measure of human capital - based on Chinese wage survey data - that better reflects the past and anticipated returns to education in China. ${ }^{2}$ Finally, our analysis is based on a carefully constructed estimate of the Chinese productive capital stock that excludes housing. Housing should not be included in a measure of the capital stock when capital is defined as an input used to produce goods and services, as it is in this context. However, in contrast to our paper, Chinese growth studies based on a Cobb-Douglas production function framework tend to use capital stock measures that include housing.

Our results suggest that Chinese growth will decelerate from around $7 \%$ currently to about $5 \%$ by 2030 , and are consistent with a gradual rebalancing of the Chinese economy characterized by a decline in the investment rate. The rest of this paper is organized as follows. In Section 2, we review the framework that we use to estimate trend output growth and its key drivers. We also present our estimates of each one of the components of trend output growth over history and compare them to those of other studies. In Section 3, we present our forecasts of Chinese trend output growth and its components out to 2030 and compare our estimates to those in the literature. Section 4 provides some concluding remarks.

\footnotetext{
${ }^{1}$ For examples of the former, see Cheremukhin et al. (2015) and references therein.

${ }^{2}$ While the literature on Chinese growth typically assumes declining marginal returns to education based on cross-country data, evidence from Chinese wage survey data suggests that the returns to education in China increase with the degree of educational attainment.
} 


\section{Key Drivers of Chinese Trend Output Growth over History}

We derive estimates of Chinese trend output growth over history using a production function approach that assumes that the supply side of output can be described by a simple CobbDouglas production function:

$$
Y_{t}=A_{t} K_{t}^{\alpha}\left(L_{t} h_{t}\right)^{1-\alpha}
$$

where $Y$ is output, $K$ is the capital stock, $L$ is labour, $h$ is human capital per worker and $\alpha$ is the share of capital income in output.

By log-linearization, equation (1) can be expressed as follows:

$$
\ln \left(Y_{t}\right)=\alpha \ln \left(K_{t}\right)+(1-\alpha) \ln \left(L_{t}\right)+(1-\alpha) \ln \left(h_{t}\right)+\ln \left(T F P_{t}\right)
$$

Taking the first difference of equation (2) will yield an equation in growth rates (where the growth rate of variable $X$ is denoted by $\hat{X})$ :

$$
\hat{Y}_{t}=\alpha \hat{K}_{t}+(1-\alpha) \hat{L}_{t}+(1-\alpha) \hat{h}_{t}+T \hat{F} P_{t}
$$

In order to abstract from the business cycle, each factor input must be assessed at its trend level (where $X^{*}$ denotes the trend level of variable $X$ ):

$$
\hat{Y}_{t}^{*}=\alpha \hat{K}_{t}^{*}+(1-\alpha) \hat{L}_{t}^{*}+(1-\alpha) \hat{h}_{t}^{*}+T \hat{F} P_{t}^{*}
$$

In the following subsections, we will present our estimates of each one of the components of Chinese trend output over history and review how each component was constructed. Data description and sources are provided in Appendix B. 


\section{$2.1 \quad$ Labour}

We use the working age population as our measure of trend labour input. The actual value of labour is measured by persons employed. Persons employed $\left(L_{t}\right)$ can be expressed as the product of the working age population $\left(P_{t}^{15-59}\right),{ }^{3}$ the labour force participation rate $\left(\operatorname{Pr}_{t}\right)$ and one less the unemployment rate $\left(U N R_{t}\right)$, as follows:

$$
L_{t}=P_{t}^{15-59} * P r_{t} *\left(1-U N R_{t}\right)
$$

When the labour force is fully employed, $\operatorname{Pr}$ and $U N R$ will be constant at their equilibrium values, and therefore

$$
\hat{L}_{t}^{*}=P_{t}^{1 \hat{5}-59}
$$

Thus, trend labour input growth is measured by the growth rate of the working age population. Estimates of the population of each age cohort both over history and into the future come from the United Nations World Population Prospects. ${ }^{4}$ China's demographic transition is striking (Figure 1). Between 1980 and 2010, the working age population increased by 386 million (70\%). However, between 2010 and 2030, it is projected to shrink by 67 million (7\%). Moreover, the workforce has aged, and will continue to age. The cohorts in the age group 15-29 made up 50\% of the workforce in 1980 and $37 \%$ in 2010, whereas they are projected to make up only $30 \%$ by 2030 .

\subsection{Human capital}

Following the standard literature, ${ }^{5}$ we construct an index of the stock of human capital $(h)$ :

$$
h=e^{\phi(s)},
$$

where $s$ is the total years of schooling and $\phi(s)$ measures the efficiency of a unit of labour with

\footnotetext{
${ }^{3}$ In contrast to advanced economies, individuals between the ages of 60 and 65 are not included in the working age population, since the retirement age for women in China is 50-55 and for men it is 60 .

${ }^{4}$ Note that we use the medium-fertility scenario.

${ }^{5}$ See, for example, Hall \& Jones (1999) and Caselli (2005).
} 
$s$ years of education relative to one without any schooling. In this equation, $\phi(s)$ measures the average marginal return of an additional year of education. We construct an index of human capital for each of the nine 5-year age cohorts of the working age population (15-59) and then use a population-weighted average to obtain an overall index for the working age population.

The educational attainment of each cohort over history (1980-2010) is derived from the Barro and Lee Educational Attainment Dataset, which gives the share that has attended and/or completed primary, secondary and tertiary education. Given the structure of the Chinese educational system, we assume that children that complete primary, secondary and tertiary education have received 6,12 and 16 years of education, respectively. In addition, we assume that those who have attended but not completed primary, secondary and tertiary education received 3, 9 and 14 years of education, respectively.

There are a number of approaches to estimating the returns to education in the literature. Bosworth \& Collins (2008) assume a constant 7\% return to each year of education, based on cross-country evidence from Psacharopoulos \& Patrinos (2004). Caselli (2005) assumes a piecewise linear function with a declining slope that implies decreasing marginal return to years of education. ${ }^{6}$ He also justifies his assumption by referring to cross-country evidence, which shows that the returns to an additional year of schooling in sub-Saharan Africa is $13 \%$, the world average is about $10 \%$ and the OECD average is about $7 \%$. Inklaar \& Timmer (2013) adopt Caselli's methodology and this is what underlies the calculation of the human capital data in the Penn World Tables. Whalley \& Zhao (2010) treat human capital in an opportunity cost of education framework. They derive human capital from the flow of graduates from different levels of education and the growth of real wages. Whalley and Zhao find a much more rapid rate of growth for the stock of human capital than elsewhere in the literature.

While cross-country data suggest declining marginal returns to education, there seems to be significant evidence that, in China, the returns to education increase with the degree of educational attainment. Drawing on data from the Urban Household Survey, Ge \& Yang (2012) find increasing returns to educational attainment both in 1992 and in 2007. In the same vein, Men et al. (2013) use data from the Urban Household Income and Expenditure Survey and find that returns to education increased with attainment both in 1988 and in 2009. Similarly, Park \& Qu (2011), using data from the China Urban Labour Survey, show

\footnotetext{
${ }^{6}$ Specifically, Caselli assumes a rate of $13 \%$ for the first four years of schooling, $10 \%$ for the next four years and $7 \%$ for additional years.
} 
that the hourly wages of middle school, high school and college graduates exhibited increasing returns to education in both the formal and informal labour markets in 2010. Averaging over these studies, we estimate that those who completed high school and college earned $17 \%$ and $74 \%$ more, respectively, than those who had only primary school education.

In addition, there is evidence that the average return to education has been close to $10 \%$, at least since the early 1990s. Using the Urban Household Income and Expenditure Survey, Ding et al. (2012) show that the return to education narrowly fluctuated between $9.7 \%$ in 2002 and 10.3\% in 2009. Similarly, Park \& Qu (2011) estimate the return to education at between 10 and 11\% based on the 2010 China Urban Labour Survey.

Drawing on the findings in the literature, we assume that the returns to primary, secondary and tertiary education were $7.7 \%, 8.9 \%$ and $13.4 \%$, respectively. These values were chosen to respect the $10 \%$ overall return and the differences between the returns to the different levels of education. We keep the returns to education constant over time.

Thus, for each given year, we compute the human capital index as follows:

$$
\begin{aligned}
\phi\left(s_{i}\right)=0 * N s_{i}+0.0769 *\left(6 C p_{i}+3\left(T p_{i}-C p_{i}\right)\right)+ & 0.0892 *\left(12 C s_{i}+9\left(T s_{i}-C s_{i}\right)\right) \\
& +0.1338 *\left(16 C t_{i}+9\left(T t_{i}-C t_{i}\right)\right)
\end{aligned}
$$

where

$$
\phi\left(s_{t}\right)=\sum_{i=1}^{i=9}\left(\frac{P_{i}}{P_{t}}\right) * \phi\left(s_{i}\right)
$$

and

$$
h=e^{\phi\left(s_{t}\right)}
$$

where $P_{i}$ is the number of people in a given age cohort and $P_{t}$ is the number of people in all of the cohorts; $T p_{i}, T s_{i}$ and $T t_{i}$ are the shares of cohort $i$ whose highest level of education attended is primary, secondary or tertiary, respectively; $C p_{i}, C s_{i}$ and $C t_{i}$ are the shares of cohort $i$ whose highest level of education attended is primary, secondary or tertiary, 
respectively, and have successfully completed that level of education; ${ }^{7}$ and $N s$ is the share of population that has no formal education. Equation (8) creates an aggregate measure of education in a single cohort, whereas equation (9) creates a similar measure for the overall population by weighting each cohort value by its share of the overall population (a total of nine cohorts was used in each time period). Finally, our human capital index is generated by equation (10).

\subsection{Capital stock}

Since there is no official capital stock series for China, we construct our own. Several papers have constructed estimates of the Chinese capital stock, including Wu (2009), Haltmaier (2013) and Perkins \& Rawski (2008). Estimates in these studies are typically based on the perpetual inventory method and rely on the official measure of investment referred to as "gross capital formation" in the Chinese National Accounts, which includes housing as part of investment.

We start by constructing a measure of the capital stock that includes housing, as is common in the literature that focuses on estimating Chinese trend output growth. The value of the capital stock in each period is thus estimated using the perpetual inventory method as follows:

$$
K_{t}=I_{t}+(1-\delta) K_{t-1}
$$

where $I$ is gross investment and $\delta$ is the depreciation rate. Since the official investment series is nominal, we use data on the contribution of investment to real GDP growth to construct a real measure of investment. The contribution of investment to growth, CIG, can be expressed as follows:

$$
C I G_{t}=\left(I_{t} / Y_{t}\right) * \Delta I_{t} / I_{t}
$$

so that real investment growth can be expressed as

\footnotetext{
${ }^{7}$ Note that for someone whose highest level of attainment was primary school, we value the returns to their education at $7.7 \%$. However, for someone who completed tertiary education, their primary education is valued at $13.4 \%$.
} 


$$
\Delta I_{t} / I_{t}=C I G_{t} *\left(Y_{t} / I_{t}\right)
$$

Using the growth rates from equation (13), we create a real investment index that we set $=100$ in 2000. ${ }^{8}$ We then multiply this index by the level of nominal investment in 2000 to obtain a series of real investment in 2000 renminbi (RMB).

We can construct the capital stock series following equation (11) once we have the depreciation rate and the initial capital stock as follows:

$$
K_{0}=I_{1} /(\delta+g)
$$

where $I_{1}$ is investment in period 1 and $g$ is the growth rate of investment in the first five years of the sample.

We construct a depreciation rate for the Chinese economy using the official rates for each asset class shown in Table 1, weighted by the share of each asset class in the capital stock. The average depreciation rate for the capital stock measure that includes housing is $7 \%$.

We compare our measure of the capital stock to those of other studies, all measured in billions of 2000 RMB. As shown in Table 2, our measure of the capital stock with housing is very similar to that in Holz (2006), and falls between that in Wu (2009) and Perkins \& Rawski (2008).

The inclusion of housing in the capital stock is problematic when capital is seen as an input that is used to produce goods and services. As discussed in Schreyer et al. (2011), conceptually there are two major types of capital stock measures, each reflecting a different role for capital. The first type of measure emphasizes capital's role in production. In this case, a measure of the capital stock as a factor input into production is required - this measure is thus often referred to as the productive capital stock. The second major type of capital captures its role as a store of wealth. Unlike the productive capital stock, its purpose in this context is not to track capital's role as a factor of production but to track its role as a set of assets with a market value. Housing ought to be included as part of the latter measure of the capital stock, but not as part of the former.

\footnotetext{
${ }^{8}$ In deriving the growth rate of real investment from the contribution data, we use the nominal investmentto-GDP ratio. Thus, we make the implicit assumption that the nominal and real investment-to-GDP ratios are equal.
} 
To construct a real measure of housing investment, we divide the National Bureau of Statistics of China's nominal investment in residential buildings series by an estimated deflator. ${ }^{9}$ We then construct a measure of the capital stock that excludes housing following the same procedure as we did for the capital stock measure including housing. Namely, we subtract real housing investment from aggregate real investment to obtain an investment series net of housing. We again use the perpetual inventory method and a depreciation rate that reflects the exclusion of housing (Table 1).

Figure 2 compares our capital stock measure with and without housing. Excluding housing makes a substantial difference to the size of the capital stock. For instance, the gap between the two measures of the capital stock is almost 11 trillion RMB in 2014 (or 17\% of GDP.) The slopes of the two lines are also different. In particular, the slope of the capital stock measure with housing is steeper, suggesting that the growth rate of the Chinese capital stock with housing is higher, implying in turn that the stock of housing has grown faster than the rest of the capital stock.

\subsubsection{Overinvestment}

China's impressive growth performance in recent years is due, in large part, to its extremely high rate of investment. As shown in Figure 3, China's investment rate is high, at almost $50 \%$ of GDP - much higher than that of most advanced and emerging-market economies and has been rising. There is a concern that such a high rate of investment may be excessive. Excessive or wasteful investment only raises output in the period in which the expenditure is undertaken, but it will have little or no impact on future growth. Assessing if, and how much, overinvestment exists in China is thus important in order to properly assess the contribution of the growth in the capital stock to output growth. Any amount of investment that is deemed to be excessive should be excluded when measuring the productive capital stock.

However, China's high investment rate does not necessarily mean that it is excessive. One would expect China's investment rate to be higher than that in advanced economies, since China's capital stock per worker is much lower. For instance, China's capital stock per worker is only about one-fifth of the U.S. level (Figure 4). Indeed, an emerging economy such as China, with massive infrastructure needs and ongoing urbanization, requires ample

\footnotetext{
${ }^{9}$ We construct this deflator by dividing the value of residential buildings completed by floor space of residential buildings completed (both these series are available in the National Bureau of Statistics of China's Chinese Statistical Yearbook). It should be noted that the residential building series starts in 1995. We then use this unit value series to construct a price index for residential buildings by setting the index equal to 100 in 2000.
} 
investment.

There are several indicators that can be used to gauge whether Chinese investment is excessive, one of which is the marginal product of capital (MPK), which measures the change in output associated with an incremental increase in the capital stock. The MPK is calculated as follows:

$$
M P K=\frac{\Delta Y}{\Delta K}=\frac{\frac{\Delta Y}{Y}}{\frac{\Delta K}{Y}}=\frac{\frac{\Delta Y}{Y}}{\frac{I}{Y}},
$$

where $K$ is the capital stock, $Y$ is GDP, $I$ is investment and $M P K$ is the marginal product of capital. As shown in Figure 5, the MPK in China has declined since 2007, implying that investment has become less efficient. However, China's MPK is in line with those of other emerging-market economies and higher than the average of advanced economies. Hence, Chinese investment does not appear to be highly inefficient relative to other countries.

It has been argued that overinvestment, at the aggregate level in China, has occurred in part because capital has been misallocated across sectors. Notably, a significant share of total investment is undertaken by state-owned enterprises (SOEs) even though the returns to capital are on average lower relative to investment carried out by private firms. Although the share of investment undertaken by SOEs has been steadily declining, it still stands at about 25\% (Figure 6). SOEs continue to account for a large share of investment, since they are given preferential access to loans (due to their implicit government guarantee) and more favourable terms (i.e., lower interest rates). There is also evidence that capital has been misallocated across sectors and has led to chronic overcapacity and very low profitability in China's heavy industry sector (Kuijs \& Qiu (2014)).

Lee et al. (2012) have argued that China is overinvesting, since its current levels of aggregate investment appear significantly out of line compared to the experience of other emerging markets around their take-off periods. Utilizing a cross-country panel, they found that this "excess investment" had grown to around 10 per cent of GDP. In a related paper, Lee et al. (2013) find that most of this excessive investment has occurred in inland provinces.

It is worth noting that the investment rate has risen in China in recent years as reliance on credit has also increased. The stock of credit has grown significantly since 2009, reaching over $190 \%$ of GDP by 2015 Q3 (Figure 7 ). ${ }^{10}$ There is concern that this period of credit expansion

\footnotetext{
${ }^{10}$ The measure of credit shown in Figure 7 is total social financing (TSF), which is a broad measure of credit to the private sector. TSF includes credit extended via the shadow banking sector.
} 
may have been excessive. A comparison of the evolution of the credit-to-GDP ratio and its trend would suggest that the recent credit expansion has indeed been excessive, since a positive gap between the Chinese credit-to-GDP ratio and its trend has emerged in recent years (Figure 8). ${ }^{11}$ As discussed in the literature on credit booms, during periods of excessive credit expansion, some investment projects that are either unproductive or too risky may be approved by lenders because lending standards loosen, perhaps due to expectations of a government bailout (Dell'Ariccia \& Marquez (2006)), and/or because the rapid expansion of loan portfolios can lead to capacity constraints (to manage risks, gather information, or assess the quality of applications) starting to bind, and new loans are approved without adequate screening (Berger \& Udell (2004)).

We attempt to account for this overinvestment due to excessive credit expansion when constructing the capital stock by comparing the measure of trend output derived using two different methodologies to estimate trend output: a Hodrick-Prescott (HP) filter and a parsimonious multivariate filter (PMVF) using credit growth as a conditioning variable. The latter can be thought of as a measure of trend output that attempts to exclude the amount of investment resulting from excessive credit growth.

The first methodology, an HP filter, is a univariate statistical approach used to derive estimates of trend output by seeking to separate output into its permanent and cyclical components. Trend output is associated with the permanent component of output, or trend output $\left(y_{t}^{*}\right)$, which is obtained by minimizing a combination of the gap between actual output $\left(y_{t}\right)$ and trend output (both in log form) and the rate of change in trend output as follows:

$$
\operatorname{Min} \sum_{t=0}^{T}\left(y_{t}-y_{t}^{*}\right)^{2}+\lambda_{1} \sum_{t=2}^{T-1}\left[\left(y_{t+1}^{*}-y_{t}^{*}\right)-\left(y_{t}^{*}-y_{t-1}^{*}\right)\right]^{2}
$$

where $\lambda_{1}$ determines the degree of smoothness of the trend and $\left(y_{t}-y_{t}^{*}\right)$ is the output gap. We set $\lambda_{1}=1600$, as is common in the literature when applying the HP filter to quarterly data. $^{12}$

The second methodology that we use, the PMVF developed by Borio et al. (2013), extends an HP filter by embedding additional information from relevant economic variables without imposing any economic relationships. ${ }^{13}$ This is in contrast to the conventional

\footnotetext{
${ }^{11}$ The trend credit-to-GDP ratio is estimated using an HP filter and setting $\lambda=40,000$.

${ }^{12} \mathrm{~A}$ value of lambda of 1600 in the HP filter with quarterly data is consistent with the common assumption that business cycle fluctuations occur within a specific frequency range (up to eight years).

${ }^{13}$ Thus, no strong priors are imposed on the data and the data are allowed to determine whether these
} 
approach based on filters that are conditioned on economic relationships. The latter can be problematic, since they are highly vulnerable to specification error.

This approach starts with an HP filter cast in state-space form by specifying the state and the measurement equations as follows:

$$
\begin{gathered}
\Delta y_{t}^{*}=\Delta y_{t-1}^{*}+\varepsilon_{0, t} \\
y_{t}=y_{t}^{*}+\varepsilon_{1, t},
\end{gathered}
$$

where $y_{t}=\ln \left(Y_{t}\right), Y_{t}$ is real GDP, and $\varepsilon_{i, t}$ is assumed to be a normally and independently distributed error with mean zero and variance $\sigma_{i}^{2}$. The functional form of the state equation (17) and the value of the parameter $\lambda_{1}$ jointly determine the relative variability of the trend output estimates.

Relevant economic information can be embedded into the output gap estimates by augmenting the measurement equation, equation (18), with additional variables (including a lag of the output gap) as follows:

$$
y_{t}-y_{t}^{*}=\beta\left(y_{t-1}-y_{t-1}^{*}\right)+\gamma^{\prime} x_{t}+\varepsilon_{2, t},
$$

where $x_{t}$ is a vector of economic variables and $\varepsilon_{2, t}$ is a normally and independently distributed error term with mean zero and variance $\sigma_{2}^{2}$. As in Borio et al. (2013), to preserve the same duration of the business cycle as implied by an HP filter where $\lambda_{1}=1600$ when we extend equation (18) to equation (19), we use a state equation of the form of equation (17) and set $\lambda_{2}=\left(\sigma_{2}^{2}\right) /\left(\sigma_{0}^{2}\right)$ such that

$$
\operatorname{var}\left(y_{t}-y_{(2), t}^{*}\right) / \operatorname{var}\left(\Delta^{2} y_{(2), t}^{*}\right)=\operatorname{var}\left(y_{t}-y_{(3), t}^{*}\right) / \operatorname{var}\left(\Delta^{2} y_{(3), t}^{*}\right),
$$

where $y_{(2), t)}^{*}$ and $y_{(3), t}^{*}$ are the trend output series from equations (18) and (19), respectively. Equation (19) is estimated by adopting a conventional Bayesian approach where the Kalman filter is used to form the likelihood of the system, the prior distributions for the parameters additional variables are informative about the cyclical component of output fluctuations. 
are specified and the posterior density function is maximized with respect to the parameters. All variables are mean-adjusted.

The results of the estimation of equation (19) with the lag of the output gap and real credit growth as explanatory variables are shown in Table 3, which is based on the following form of equation (19):

$$
y_{t}-y_{t}^{*}=\beta_{1}\left(y_{t-1}-y_{t-1}^{*}\right)+\gamma_{1} C R E D_{t}+\varepsilon_{2, t} .
$$

We use two different versions of credit in the estimation: total social financing and total social financing excluding the liabilities of property developers. The former will be used to construct our estimate of overinvestment for the capital stock including housing, whereas the latter will be used to construct our estimate of overinvestment for the capital stock excluding housing. ${ }^{14}$ As shown in Table 3, the coefficients on the explanatory variables are statistically significant; therefore, the lag of the output gap, and more importantly, the lag of real credit growth in the economy, are adding useful information in the estimation of trend output.

As shown in Figure 9, a gap emerged in recent years between the measure of trend output derived from an HP filter and that derived from the PMVF with real credit growth as a conditioning variable. We interpret this gap as being the result of overinvestment fuelled by excessive credit expansion. The gap was largest in 2014, when it accounted for about $1.5 \%$ of GDP or about 3.3\% of total investment. Our estimate of overinvestment for 2014 is significant but lower than the 10\% suggested by Lee et al. (2013).

Adjusting for overinvestment using our estimates leads to a lower measure of the capital stock, as shown in Figure 10, which depicts the measure of the capital stock excluding housing to that excluding housing and accounting for overinvestment due to excess credit expansion.

\subsection{Total factor productivity}

To derive an estimate of trend TFP growth, we first obtained the growth rate of actual TFP growth as the residual from equation (3) using actual GDP, capital stock, labour and human

\footnotetext{
${ }^{14}$ We constructed a series for the total liabilities of property developers by multiplying the share of residential real estate investment over total real estate investment by the total liabilities of the real estate sector. All data are from the National Bureau of Statistics of China.
} 
capital growth. ${ }^{15}$ We then constructed an index for the level of TFP where we set TFP equal to 100 in the first year and grew it out by using the growth rate obtained from equation (3). Next, we used an HP filter to find a trend TFP level of the series obtained. The growth rate of the filtered TFP series is taken to be the trend growth rate of TFP.

We assume that labour's share of income, $(1-\alpha)$, is equal to 0.5 , in line with its average in recent years. It is also roughly in line with the labour share in other emerging markets, which tends to be lower than that in advanced economies (International Labour Organization (2013)).

We constructed trend TFP growth series for our three measures of the capital stock: our measure that includes housing, our measure that excludes housing and our measure that excludes housing and accounts for overinvestment. As shown in Figure 11, the actual TFP series are quite volatile but the trended series are fairly smooth. ${ }^{16}$ All the series are humpshaped, with TFP growth steadily increasing until it peaks in 2006, and then gradually declining thereafter.

In order to explain the evolution of Chinese TFP growth over history, we decompose TFP growth into key factors drawing on the literature on the determinants of TFP growth. This literature suggests that productivity is positively related to foreign direct investment (FDI), openness, research and development (R\&D) expenditures, and sectoral labour shifts. TFP growth can be related to growth in the stock of FDI and to import growth, since both are associated with technology spillovers (Lee et al. (2011)). In estimating the contribution of FDI and imports to TFP growth, we rely on work by Lee et al (2011) that suggests that a $10 \%$ increase in the real FDI stock raises TFP growth by 2.2 percentage points and that real import growth of 10 percent increases TFP growth by 0.7 percentage points. Domestic spending on R\&D can also promote TFP via technology transfer. To estimate the contribution of R\&D to TFP growth, we rely on work by Griffith et al. (2004) that suggests a 1 percent increase in R\&D spending raises TFP growth by close to 0.7 percentage points.

Since the early 2000s, output per person in manufacturing and services in China has been 4-5 times as high as in agriculture (Figure 12). These high and persistent productivity differentials suggest that significant gains can be made from reallocating labour across sectors. Indeed, the share of employment in agriculture fell from 50\% in 2000 to $30 \%$ in

\footnotetext{
${ }^{15}$ We assume that the growth rates of the capital stock and human capital are equal to their trend growth rates.

${ }^{16}$ The TFP growth series corresponding to the capital stock measure that accounts for overinvestment are not shown in Figure 11, since they are very similar to those corresponding to the capital stock measure excluding housing.
} 
2013, when $40 \%$ of employment was in services and $30 \%$ was in manufacturing. We estimate the contribution to TFP growth from the sectoral reallocation of labour by creating a counterfactual under which the employment shares are frozen at their 2000 levels but allow the productivity within each sector to evolve as per history. The resultant difference in per capita GDP growth between the frozen share counterfactual and the actual data is the contribution to TFP growth from the sectoral reallocation of labour. As shown in Figure 13, these four factors broadly explain the movements in Chinese trend TFP growth from 2000 to 2014. Between 2000 and 2014, TFP growth averaged about 3.3\%. Of this, we find that 1.6 percentage points was due to the sectoral reallocation of labour, 1.0 percentage points was due to R\&D, 0.9 percentage points were due to openness (import growth), 0.3 percentage points were due to FDI and -0.5 percentage points remain unexplained.

\subsection{Trend output growth over history}

Now that we have assessed each factor input at its trend, we can construct our measure of trend output growth over history following equation (4). We present results for our three measures of the capital stock: our measure that includes housing, our measure that excludes housing and our measure that excludes housing and accounts for overinvestment. We set $\alpha=0.5$. A decomposition of the estimates of trend output growth suggests that both capital accumulation and TFP growth have been the main factors driving overall trend output growth in China since the mid-1990s (Table 4 and Figure 14).

The contribution of capital growth is somewhat lower over the 2001-2010 period when using a measure of the capital stock that excludes housing, since the housing stock has grown more rapidly than the productive capital stock throughout most of the sample. As shown in Figure 15, residential investment as a share of GDP has increased five-fold in China since the mid-1990s and China now invests a much larger share of its GDP in housing relative to other countries (Figure 16). Indeed, following the privatization of the housing stock in China in the mid-1990s, the demand for upgraded housing grew significantly as income growth surged, spurring housing investment. Moreover, demand for housing was also fuelled by a steady rise in the urbanization rate (Figure 15). When using the measure of the capital stock that excludes housing and accounts for overinvestment, the growth rate of the capital stock is found to be somewhat even lower, but not by enough to alter the contribution of capital stock growth to trend output growth.

Other studies in the literature have also found that capital stock growth and TFP growth 
were the main drivers of trend output growth since the mid-1990s (Table 5). Most of these studies, however, have found a higher contribution coming from capital growth, and hence a lower contribution coming from TFP growth, than we have. This difference in results is likely due to differences in how the capital stock is measured and underscores the importance of exercising care in constructing a measure of the Chinese capital stock.

Another important difference between our results and those in the literature relates to the contribution from human capital growth. The studies that use a growth accounting framework with the same four inputs as we do (i.e., He \& Kuijs (2007) and Kuijs (2009)) find a smaller contribution from human capital growth and a larger contribution from labour growth. These studies assume lower returns to education than we do and appear to be based on cross-country evidence that finds lower and decreasing returns to education. As discussed earlier, we base our assumptions about the returns to education in China on Chinese wage survey data and assume that the returns to education are increasing and are higher than typically assumed in the growth accounting literature.

\section{Forecasting Trend Output Growth to 2030}

Although the Chinese economy is expected to moderate, there is no clear consensus regarding the extent and pace of the anticipated slowdown. Our approach in this paper is to construct forecasts of Chinese trend output growth and its key components over the period from 2016 to 2030 using the same production function approach framework used for the derivation of the estimates over history. We build our forecasts of trend GDP growth using a bottom-up approach based on forecasts that we construct for each one of the components of trend GDP growth (i.e., capital stock growth, labour growth, human capital stock growth and TFP growth).

\subsection{Forecasting labour and human capital growth}

Obtaining our forecast of trend labour input growth is straightforward. As with the historical series, we measure trend labour input growth using the growth rate of the working age population. We obtain this data from the United Nations World Population Prospects. As shown in Figure 1, the working age population is expected to decline moderately over the forecasting horizon. ${ }^{17}$

\footnotetext{
${ }^{17}$ In our analysis, we abstract from measures that could affect the labour force participation rate. To the extent that policies might be introduced that increase the participation rate by, say, increasing the retirement
} 
In order to forecast human capital growth, we need to make assumptions for the educational attainment of the 15-19-, the 20-24- and the 25-29-year-old cohorts. The attainments of the older cohorts are simply carried forward from their 2010 levels as they age - this pattern is observed over history in the Barro and Lee dataset. We assume that for the 15-19-year-old cohort in 2015 and subsequent years, $0.1 \%$ have no education and $2.9 \%$ have only primary education. In making this assumption, we simply carry forward the observed characteristics of that cohort in 2010. To forecast secondary and tertiary attainment, we extrapolate future Chinese secondary and tertiary enrolment rates based on the relationship between enrolment rates and per capita incomes of middle and high-income countries (see Figures 17-18). We foresee an increase in secondary enrolment rates between 2010 and 2030 from $83 \%$ to $92 \%$. Similarly, we forecast that tertiary enrolment will rise from $23 \%$ to $44 \%$ over the same period.

We use the historical relationship between enrolment rates and tertiary attendance to estimate $T t$, the share of the population that attended tertiary education, into the future. $T s$, the share of the population that has attended secondary education, is calculated as a residual in $N s+T p+T s+T t=100$. We then apply historical completion rates for each age cohort to derive $C s$ and $C t$, the shares of the population that have completed secondary and tertiary education, respectively. Our estimates of average historical and future years of educational attainment are presented in Figure 19. It shows that average years of education increased from 5.9 in 1980 to 10.3 in 2010 (75\%). Most of this increase came from a large increase in secondary school attainment. Both secondary and tertiary attainment increased sharply in 1995 from 1990. Looking forward, we expect that average years of education will increase to 11.9 by 2030 (by 16\% from 2010). All of this increase will be the result of greater tertiary education attainment, as average years of tertiary education will rise from 1.4 in 2010 to 3.1 in 2030 (123\%). Figure 20 shows our past and future values of $h$. Since we hold the returns to educational attainment constant both over the past and into the future, the growth rate of the human capital index mirrors that of the average years of education.

\subsection{Forecasting capital stock growth}

One approach to forecasting the Chinese capital stock is to rely on coefficients obtained from a cross-country estimation. For example, Erumban et al. (2013) project capital stock and TFP growth in a large sample of countries. However, estimates from such a framework age, we would be underestimating labour input growth and hence GDP growth. 
tend to significantly underestimate Chinese capital stock growth given that it is based on coefficients that represent the average from a large sample of countries and the Chinese economy has been an outlier for many years. We thus believe that a better approach is to draw on the early experiences of two other Asian countries, both of whom had periods of rapid capital accumulation and growth, to anchor our forecast of the Chinese capital stock. Specifically, we assume that the increase in China's capital-labour ratio will be proportional to those of Japan and Korea at similar levels of development (Figure 21). Given our forecasts of the capital-labour ratio and the labour force for China, we can then back out a forecast of the capital stock. To ensure comparability, we use measures of the productive capital stocks for all three countries (i.e., excluding housing) and the working age population as our measure of labour. The Japanese and Korean productive capital stock measures are taken from the OECD and the working age population is taken from the United Nations World Population Prospects.

\subsection{Forecasting TFP growth}

As we did to explain the evolution of Chinese TFP growth over history, we rely on the literature that suggests that productivity is positively related to FDI, R\&D expenditures, import growth and sectoral labour shifts to forecast TFP growth. More specifically, our forecast of TFP growth is based on the aggregation of forecasts that we construct for the contribution of TFP growth related to FDI, R\&D expenditures, import growth and sectoral labour shifts.

The ratio of R\&D to GDP in China has increased very rapidly from $1.5 \%$ in 2008 to $2.0 \%$ in 2013. We gradually grow Chinese R\&D spending from an actual $2.0 \%$ of GDP in 2013 to $2.5 \%$ of GDP in 2018 and then leave it at that level until 2030 (Figure 22). This is essentially the average R\&D/GDP ratio in advanced countries. According to Griffith et al.'s (2004) coefficient of 0.669 , our R\&D forecast implies a contribution of $1.4 \%$ to TFP growth in 2014, rising to $1.7 \%$ in 2018 and remaining there until 2030. R\&D spending is the single largest contributor to forecasted TFP growth.

The real stock of FDI grew at an average annual rate of $19 \%$ between 2004 and 2014 and at $6 \%$ between 2009 and 2014. We assume that growth slows gradually from $6 \%$ in 2015 to $5 \%$ in 2030 (Figure 23). The real FDI stocks in Japan and Korea have been growing at roughly $5 \%$ in recent years, pinning down a reasonable endpoint for our forecast. Given the elasticity of TFP growth with respect to FDI growth proposed by Lee et al. (2011) (0.0218), 
this profile of FDI growth adds 0.13 percentage points to TFP growth in the near term, slowing to 0.11 percentage points by 2030 .

Real import growth grew at an average annual rate of $8 \%$ between 2003 and 2013 . It is forecast to gradually slow from $7.8 \%$ in 2015 to $5 \%$ in 2030 (Figure 24). This is a conservative forecast. Between 2000 and 2014, the elasticity of real import growth with respect to real GDP growth was 1.8. Going forward, we use an elasticity of 1.4. According to the coefficient suggested by Lee et al. (2011), our forecasted import growth implies a contribution to TFP growth of $0.5 \%$ in 2015 , falling to $0.3 \%$ by 2030 .

As noted above, about 30\% of China's employment is currently in agriculture. Drawing on the experience of other countries, we expect this share to fall as per capita income rises. Given our real GDP profile and population growth, we expect per capita GDP growth to average $5.8 \%$ over 2015-2030. At this rate, China's per capita GDP would exceed US $\$ 30,000$ in PPP terms. Based on the experience of Malaysia, Korea, Brazil, Portugal, Greece and Italy, this would imply a fall in the agricultural share of employment to 7 percent. However, since China has typically had more labour devoted to agriculture than these countries have (Figure 25), we reduce its share more gradually, to $13 \%$ by 2030 . We calculate the effect of the sectoral reallocation of labour on TFP in the following manner:

- We calculate a baseline level of output based on the current sectoral distribution of labour and the current levels of sectoral productivity. We then calculate an alternative scenario based on the agricultural share of employment declining as per the profile in Figure 25, with the share in services growing by a corresponding amount. The manufacturing share is assumed to be constant. Sectoral productivity levels are assumed to be the same across the two scenarios. The differences in the levels of output are seen as contributions to the level of TFP. The annual growth in the level difference is seen as a reflection of the contribution of labour reallocation to TFP growth.

- Sectoral reallocation adds 1.3 percentage points to TFP in the near term, tapering to 0.8 percentage points by 2030 .

Adding the forecasts for these four elements together, we get the profile for TFP growth illustrated in Figure 13. It shows a cyclical pickup in TFP growth to 3.5\% in 2015-16, before declining to $2.9 \%$ in 2030 . 


\subsection{Forecasting trend output growth}

Once we have constructed forecasts for capital, labour, TFP and human capital growth, we can build our forecasts of trend output growth following equation (4). As shown in Table 6 , Chinese trend output growth is forecast to decline gradually over the next 15 years to somewhere around 5\%. A smaller contribution from capital accumulation explains most of the slowdown in trend output growth, from an average of 7\% in 2016-20 to 4.9 percent in 2026-30, although a modest slowdown in TFP growth and a larger decline in labour input growth also play a role. Human capital growth is expected to grow at a steady rate throughout the forecasting period. Forecast comparisons with other studies, shown in Table 7 , suggest that our results are broadly in line with the literature in that most studies forecast a decline in trend output growth, driven by a reduction in capital stock growth.

As laid out in its "Third Plenum Blueprint," the Chinese government plans to undertake sweeping reforms in coming years aimed at reducing distortions in the Chinese economy and rebalancing economic activity away from excessive investment and toward consumption. Years of rapid capital accumulation have brought about high economic growth in China but have also created imbalances in the economy. In particular, the investment rate has risen to $50 \%$ of GDP, whereas the share of consumption in GDP has declined significantly, and is now well below international standards at about 35\%. As discussed by Dollar (2014), the reforms sketched out in the "Third Plenum Blueprint" that are likely to have the most effect on rebalancing the economy from extensive to intensive growth fall into four areas: liberalization of the household registration system (hukou); intergovernmental fiscal reform; financial liberalization; and opening up China's service sector to competition.

Our forecasting results can be used to gain some insights into whether, and to what extent, the Chinese economy is expected to rebalance over the next decade and a half. Given our forecasts for the capital stock and GDP growth, and assuming the same depreciation rate over the forecasting horizon as over history, we can back-out a profile for the investment-toGDP ratio. Our forecasting results are consistent with a gradual rebalancing of the Chinese economy characterized by a decline in the investment rate from close to $50 \%$ currently to around $25 \%$ by 2030 . However, these results are implicitly contingent on the implementation of productivity-enhancing reforms that support robust TFP growth. 


\section{Concluding Remarks}

This paper presents estimates of Chinese trend output growth over history and out to 2030 using a production function approach that decomposes this estimate into four key drivers: capital stock growth, labour growth, human capital growth and TFP growth. Our paper distinguishes itself from existing work in that our analysis is based on a carefully constructed estimate of the Chinese productive capital stock and a measure of human capital - based on Chinese wage survey data - that better reflects the past and anticipated returns to education in China. Moreover, we draw on the literature on the determinants of TFP growth to create a forecast of Chinese TFP growth based on the aggregation of forecasts of its key factors.

Our results suggest that Chinese growth will decelerate from around $7 \%$ currently to about $5 \%$ by 2030, and are consistent with a gradual rebalancing of the Chinese economy characterized by a decline in the investment rate. Our results are also broadly in line with the literature in that most studies forecast a decline in trend output growth, driven by a reduction in capital stock growth.

\section{References}

Berger, A., \& Udell, G. (2004). The institutional memory hypothesis and the procyclicality of bank lending behavior. Journal of Financial Intermediation, 13, 458-95.

Borio, C., Disyatat, P., \& Juselius, M. (2013). Rethinking potential output: Embedding information about the financial cycle. BIS Working Paper no. 404.

Bosworth, B., \& Collins, S. (2008). Accounting for growth: Comparing China and India. Journal of Economic Perspectives, 22, 45-66.

Caselli, F. (2005). Accounting for cross-country income differences. In P. Aghion, \& S. Durlauf (Eds.), Handbook of Economic Growth, Volume 1A. Elsevier.

Cheremukhin, A., Golosov, M., Guriev, S., \& Tsyvinski, A. (2015). The economy of people's republic of China from 1953. Https://scholar.princeton.edu/sites/default/files/golosov/files/china.pdf.

Dell'Ariccia, G., \& Marquez, R. (2006). Lending booms and lending standards. The Journal of Finance, 51, 2511-2546. 
Ding, X., Qiumei, Y., \& Hongxia, Y. (2012). Studies on the rate of return to education and its evolution in urban China in the current century. Education Development Research, November 2012 (Chinese).

Dollar, D. (2014). Sino shift. Finance and Development, 51.

Dollar, D., \& Wei, S.-J. (2014). Das (wasted) kapital: Firm ownership and investment efficiency in China. IMF Working Paper 07/9.

Eichengreen, B., Park, D., \& Shin, K. (2012). When fast-growing economies slow down: International evidence and implications for China. Asian Economic Papers, 11, 42-87.

Erumban, A. A., de Vries, K., \& van Ark, B. (2013). New measures of global growth projection for the conference board global economic outlook 2014. The Conference Board, November 2013.

Ge, S., \& Yang, T. (2012). Changes in China's wage structure. IZE Discussion paper No. 6492, Forschungsinstitut zur Zukunft der Arbeit/Institute for the Study of Labor, April 2012.

Griffith, R., Redding, S., \& Reenen, J. V. (2004). Mapping the two faces of r and d: Productivity growth in a panel of OECD industries. The Review of Economics and Statistics, $86,883-895$.

Guo, K., \& N'Diaye, P. (2014). Is China's export-oriented growth sustainable. IMF Working Paper 07/9.

Hall, R., \& Jones, C. (1999). Why do some countries produce so much more ouptut per worker than others? Quarterly Journal of Economics, 114, 83-116.

Haltmaier, J. (2013). Challenges for the future of Chinese economic growth. International Finance Discussion Papers no. 1072, Board of Governors of the Federal Reserve System.

He, J., \& Kuijs, L. (2007). Rebalancing China's economy-modeling a policy package. World Bank China Research Paper no. 7, September 2007.

He, J. and S. Li and S. Polaski (2007). China's economic prospects: 2006-2020. Carnegie Papers, no. 83.

Holz, C. (2006). New capital estimates for China. China Economic Review, 17, 142-85. 
Inklaar, R., \& Timmer, M. (2013). Capital, labour and tfp in PWT8.0. Groningen Growth and Development Centre, University of Groningen, July 2013.

International Labour Organization (2013). Global wage report. International Labour Organization.

Kuijs, L. (2009). China through 2020-a macroeconomic scenario. World Bank China Research Paper no. 9, June 2009.

Kuijs, L., \& Qiu, T. (2014). Trends in profitability in industry. RBS Top View - China, 27 March 2014.

Lee, H., Lee, J., \& Kim, H. (2011). Foreign direct investment, technology diffusion and host country productivity growth. Asian Development Bank Working Paper no. 272.

Lee, I., Syed, M., \& Xueyan, L. (2012). Is China over-investing and does it matter? IMF Working Paper no. 12/277, November 2012.

Lee, I., Syed, M., \& Xueyan, L. (2013). China's path to consumer-based growth: Reorienting investment and enhancing efficiency. IMF Working Paper no. 12/83, March 2013.

Men, X., Shen, K., \& Xue, S. (2013). Economic reform, education expansion, and earnings inequality for urban males in China, 1988-2009. Journal of Comparative Economics, 41 , $227-244$.

OECD (2014). Long-term baseline projections database, no. 95. OECD, Paris, May 2014.

Park, A., \& Qu, X. (2011). Returns to education and informal labour markets in urban China: Evidence from culs3. Mimeo.

Perkins, D., \& Rawski, T. (2008). Forecasting China's economic growth to 2025. In L. Brandt, \& T. Rawski (Eds.), China's Great Economic Transformation. Cambridge University Press.

Pritchett, L., \& Summers, L. (2014). Asiaphoria meets regression to the mean. NBER Working Paper no. 20573.

Psacharopoulos, G., \& Patrinos, H. (2004). Returns to investment in education: A further update. Education Economics, 12, 111-134. 
Schreyer, P., Dupont, J., Koh, S., \& Webb, C. (2011). Capital stock data at the OECD status and outlook. OECD, Paris: www.oecd.org/std/productivity-stats/48490768.doc.

Wang, F. (2012). Racing towards the precipice. China Economic Quarterly.

Whalley, J., \& Zhao, X. (2010). The contribution of human capital to China's economic growth. NBER Working Paper 16592, December 2010.

World Bank (2013). China 2030: Building a modern, harmonious, and creative society. The World Bank and the Development Research Center of the State Council of the People's Republic of China.

World Bank (2015). China economic update. The World Bank.

Wu, Y. (2009). China's capital stock series by region and sector. University of Western Australia Business School Discussion Paper no. 09.02.

Zheng, J., Bigsten, A., \& Hu, A. (2009). Can China's growth be sustained? a productivity perspective. World Development, 37. 


\section{Appendix A: Figures and Tables}

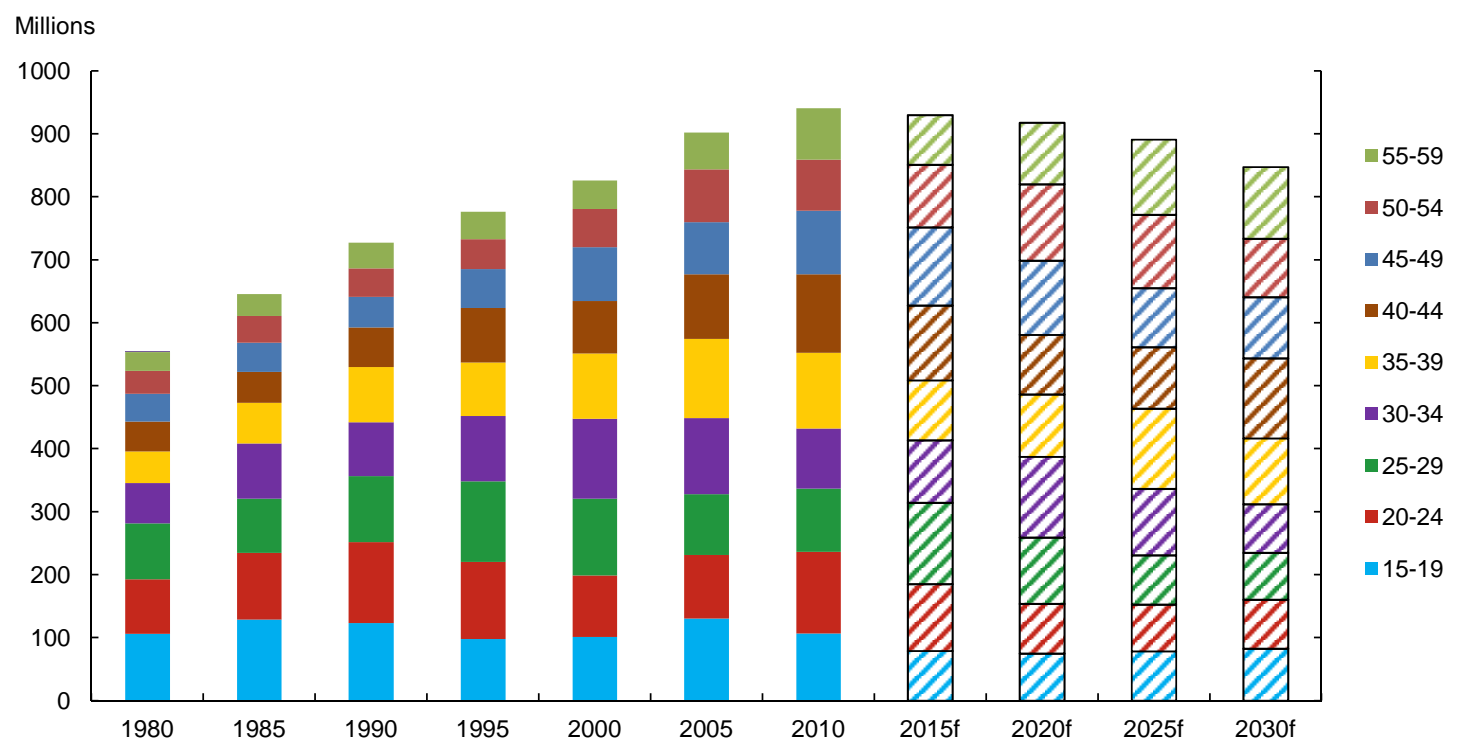

Source: United Nations

Figure 1: Working Age Population in China: 1980-2030

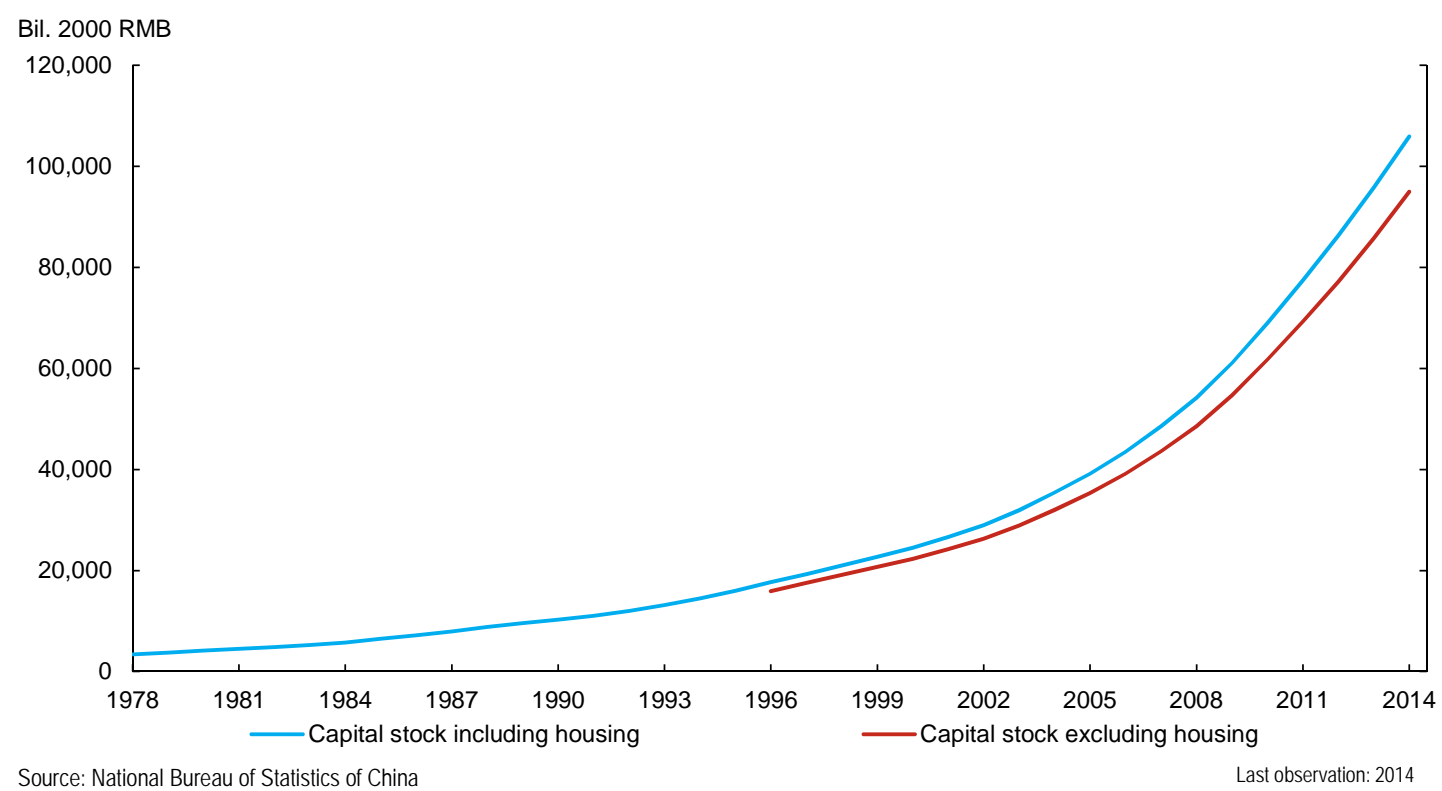

Figure 2: Comparison of Capital Stock Measures 


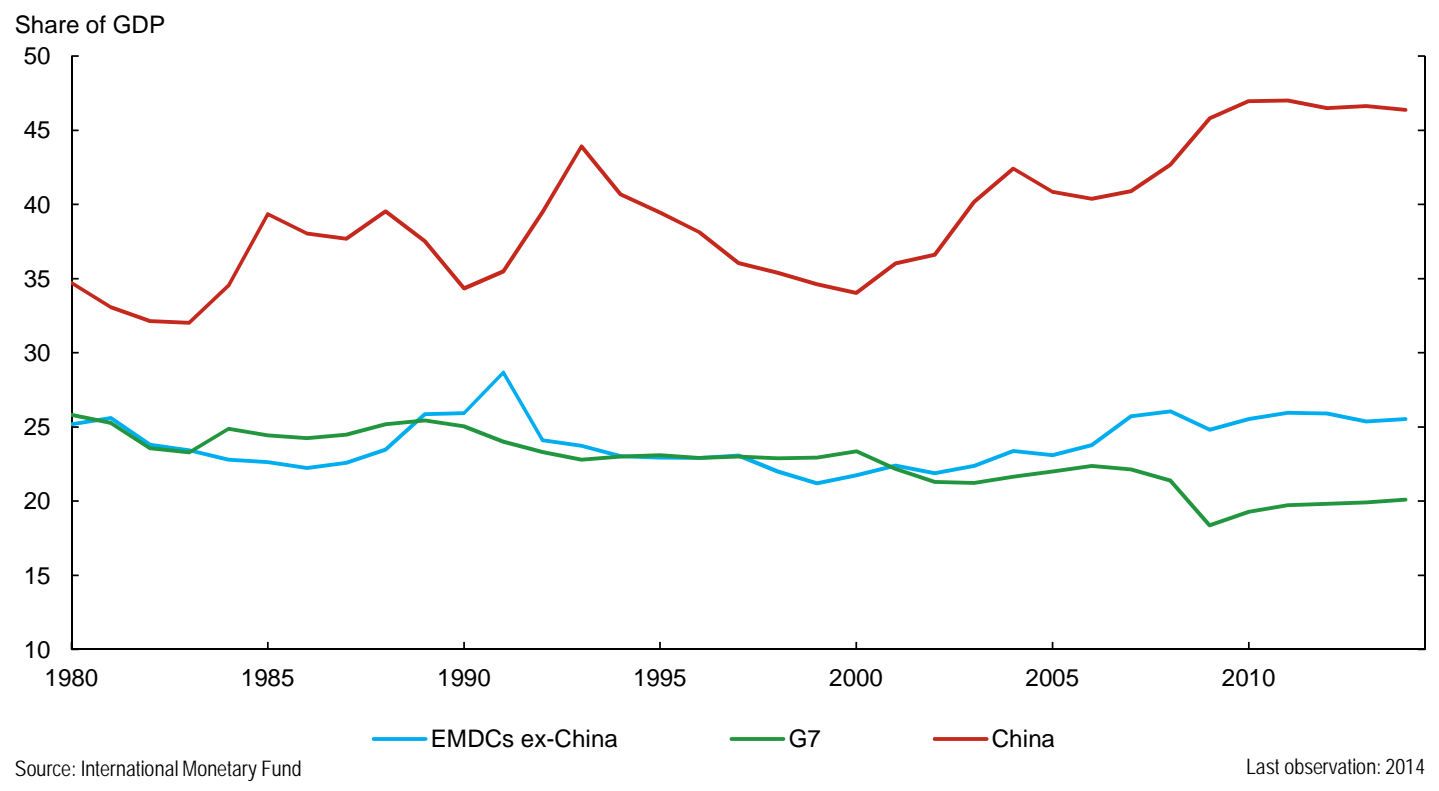

Figure 3: Investment-to-GDP ratio

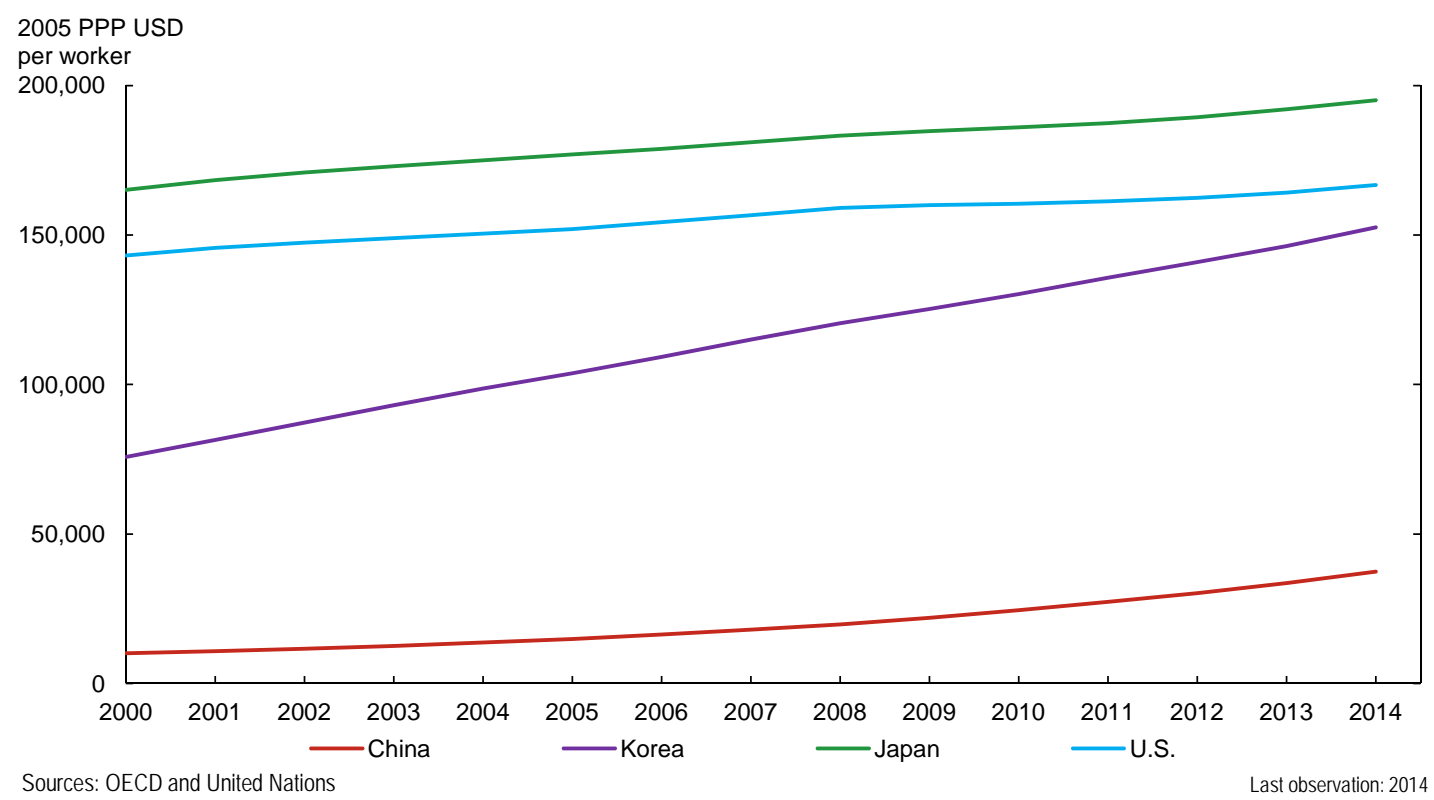

Figure 4: Capital stock per worker 


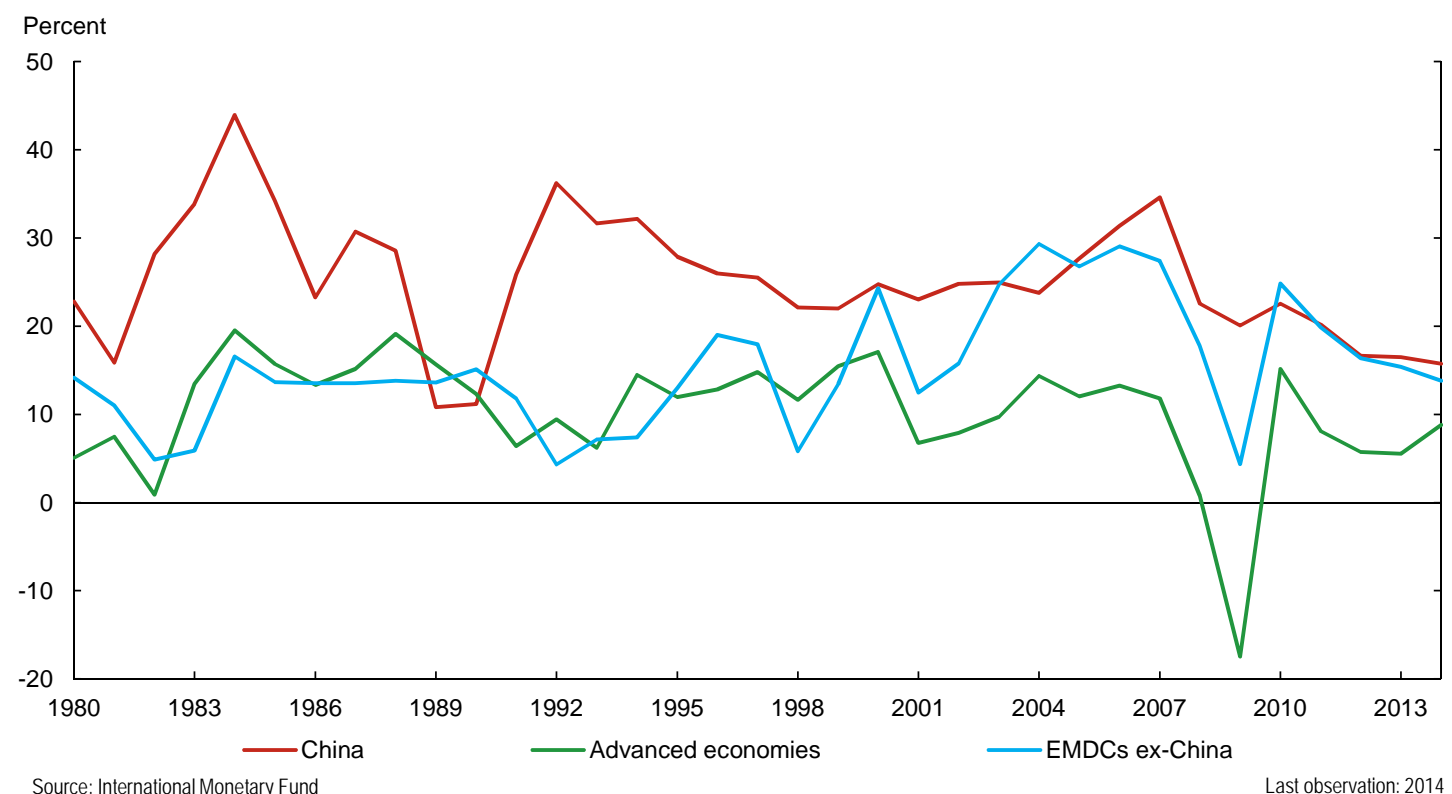

Figure 5: Marginal product of capital

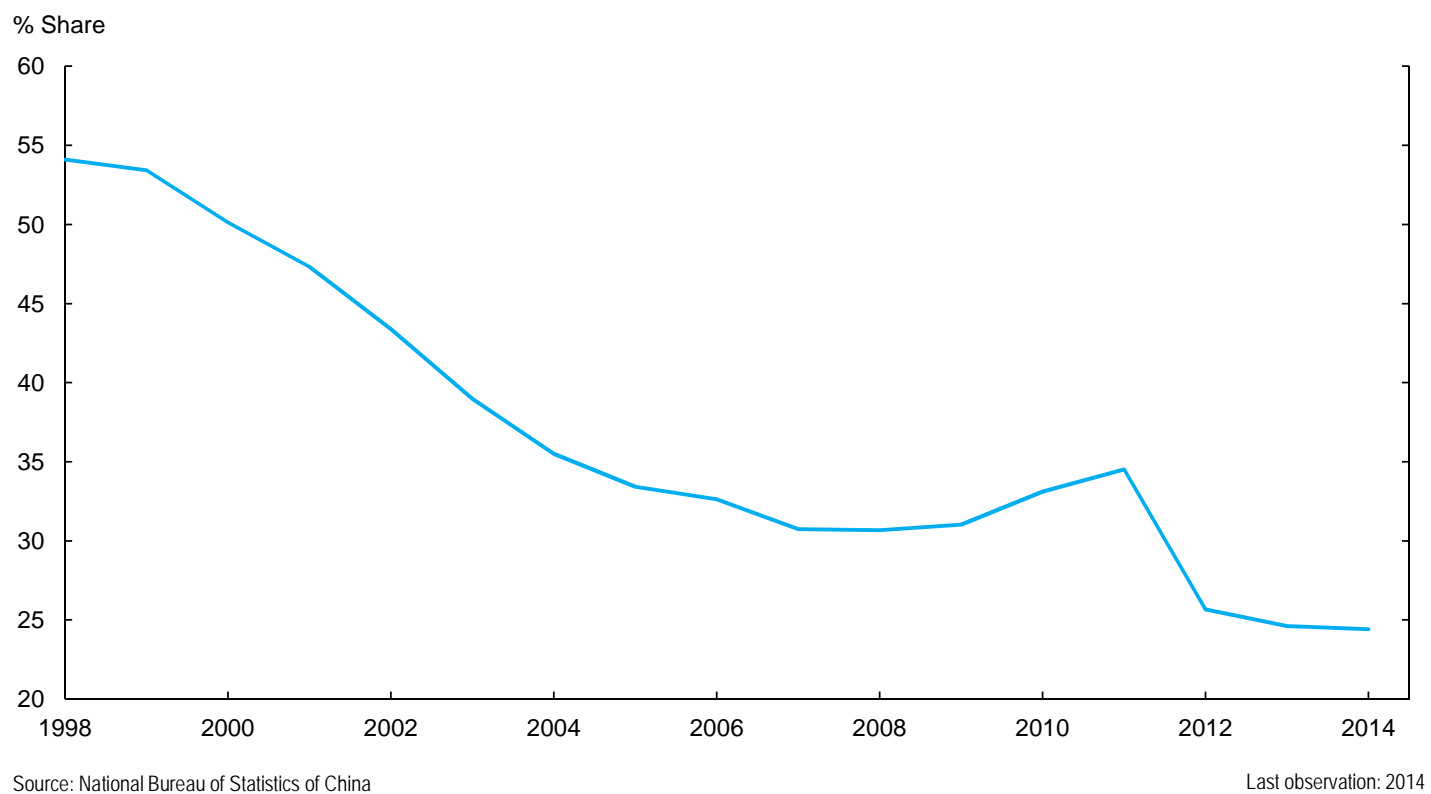

Figure 6: Share of Chinese investment undertaken by state-owned enterprises 


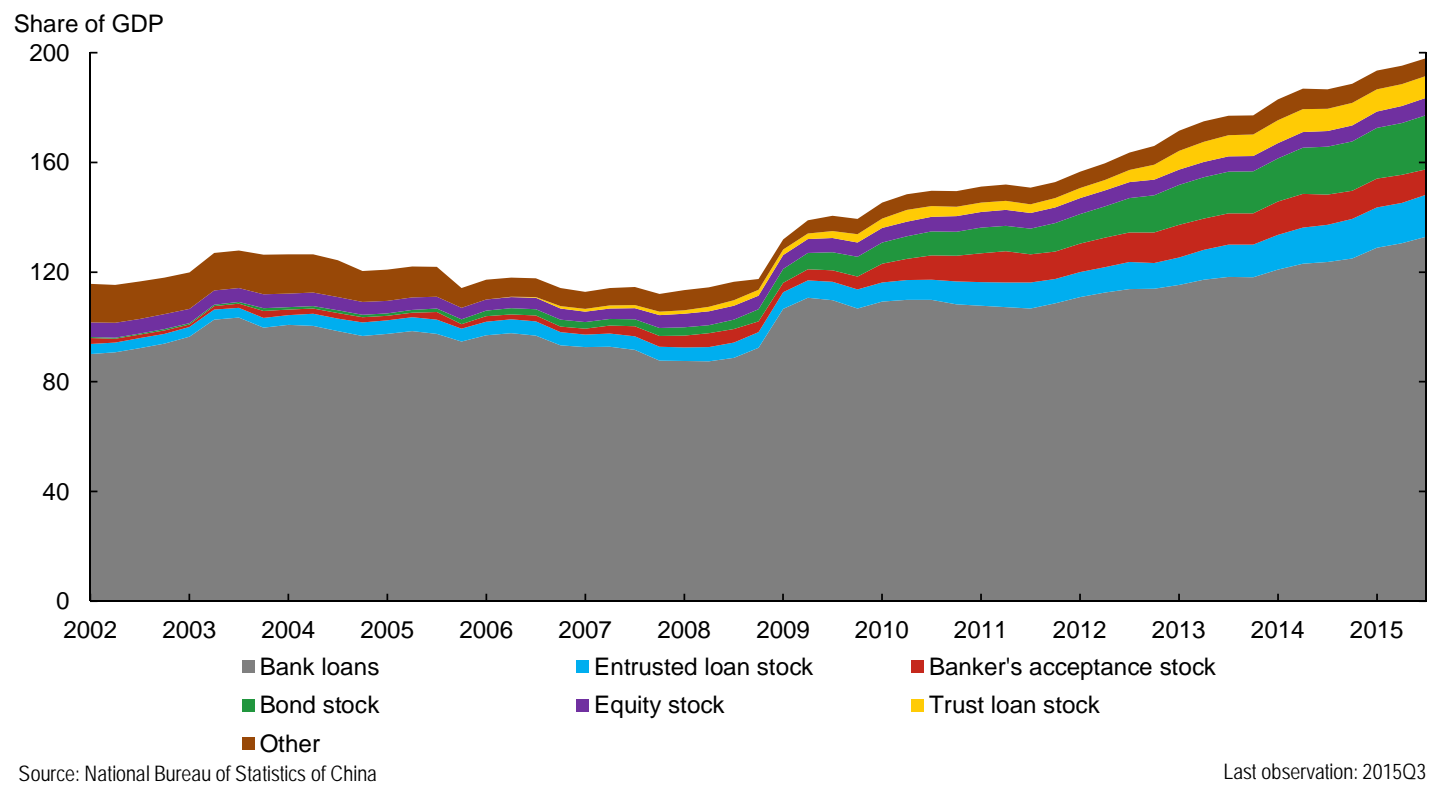

Figure 7: China's stock of total social financing (TSF) as a share of GDP

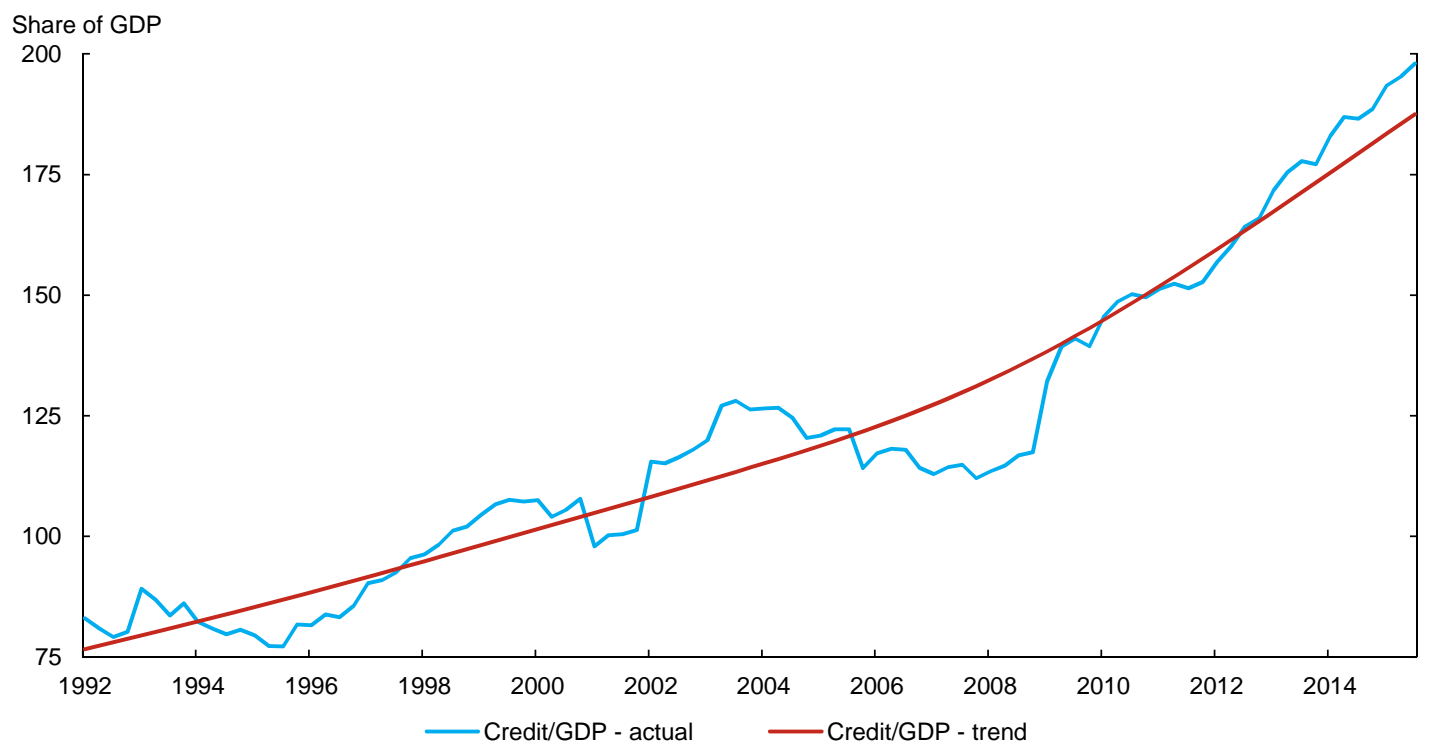

Sources: Bank for International Settlements and National Bureau of Statistics of China

Last observation: $2015 \mathrm{Q} 3$

Figure 8: China's credit-to-GDP ratio: actual and trend 


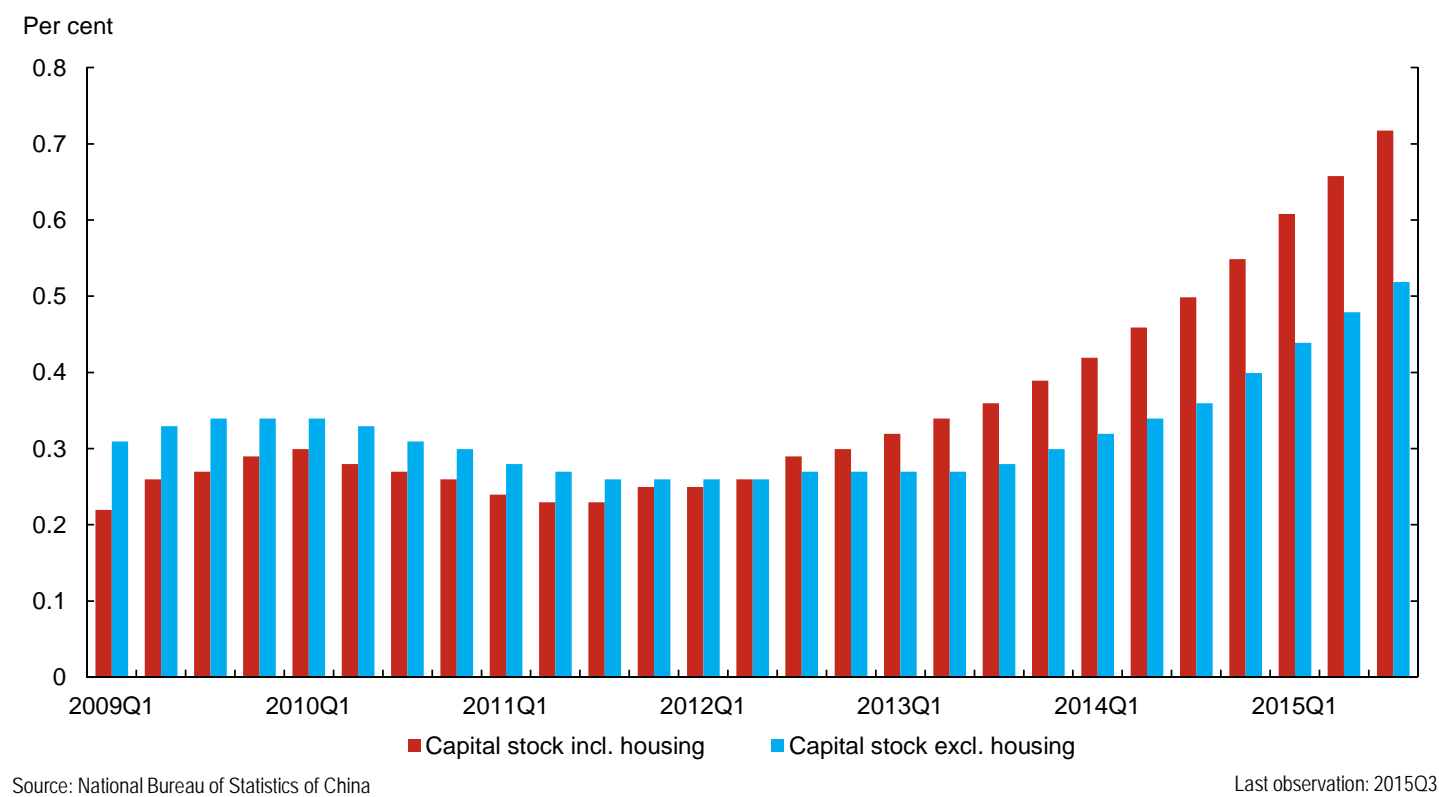

Figure 9: Difference in level of trend output: HP versus PMVF

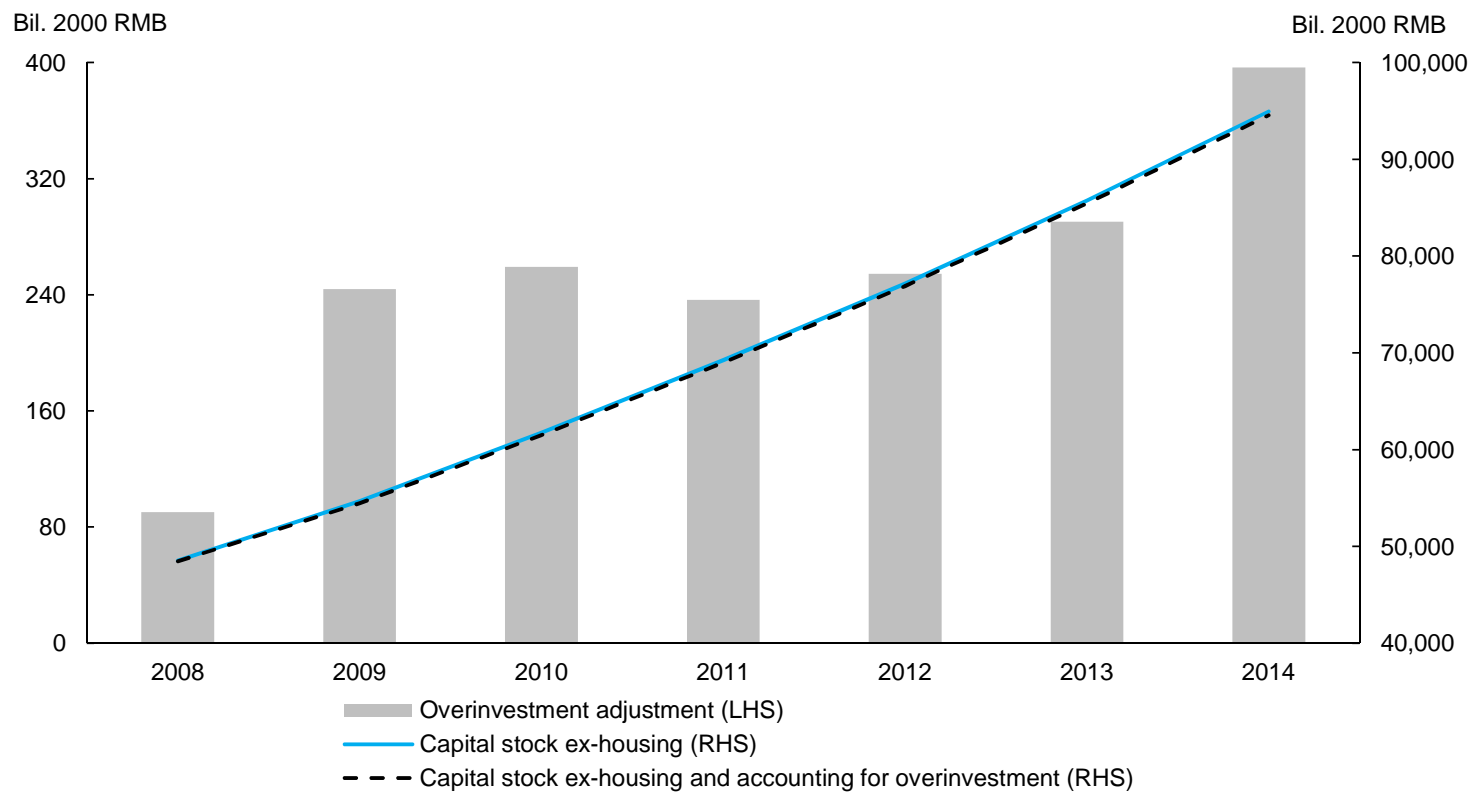

Figure 10: The effect of overinvestment on the capital stock 


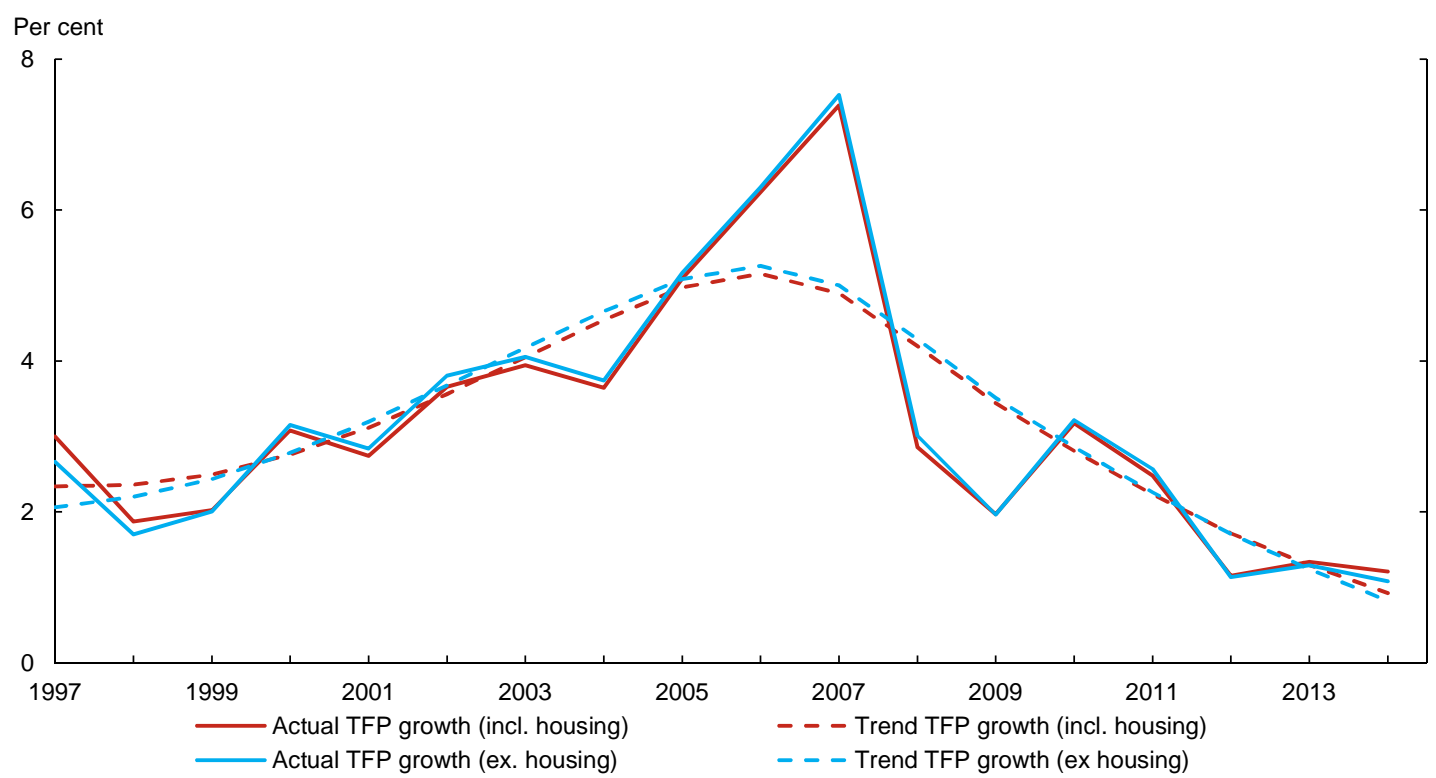

Figure 11: TFP growth: actual versus trend

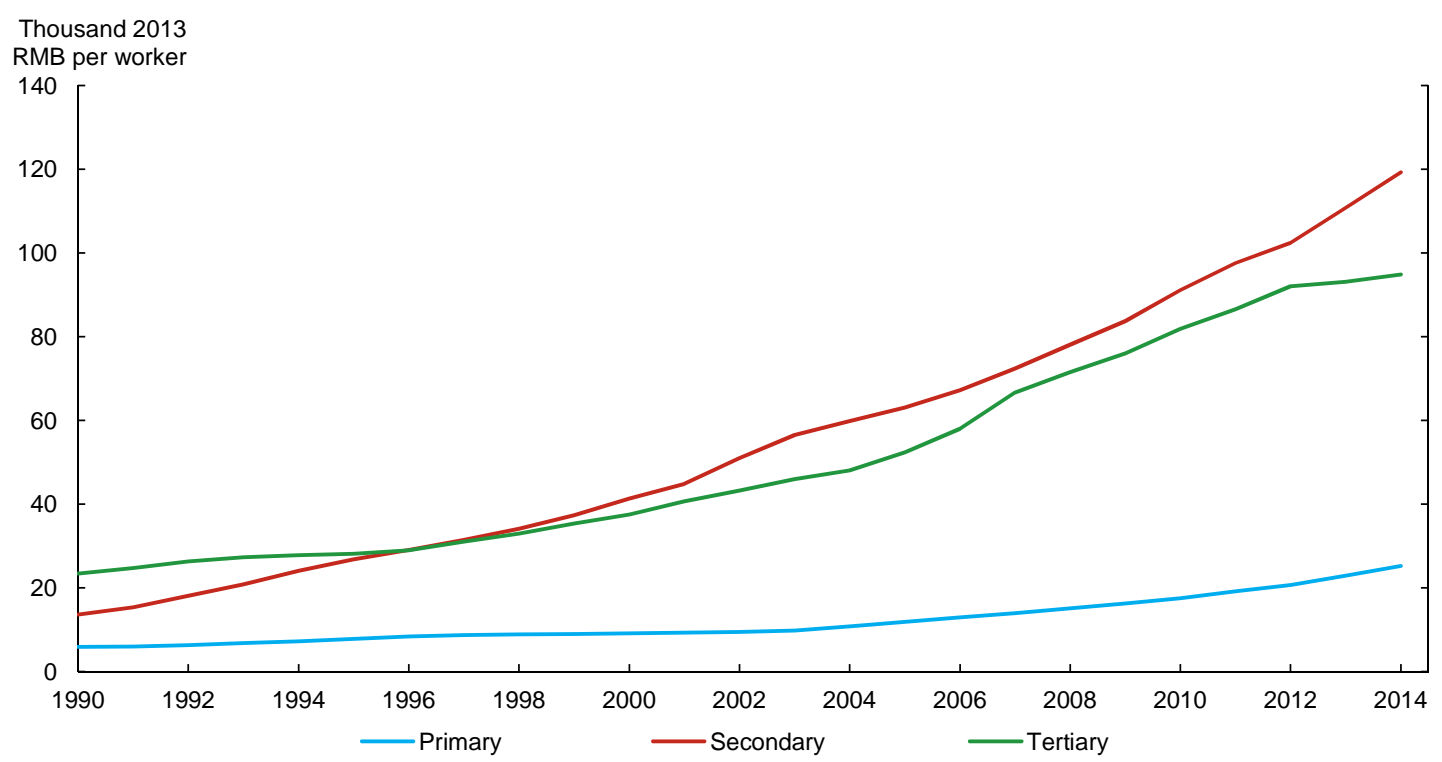

Sources: National Bureau of Statistics of China and authors' calculations

Figure 12: Productivity levels per worker 


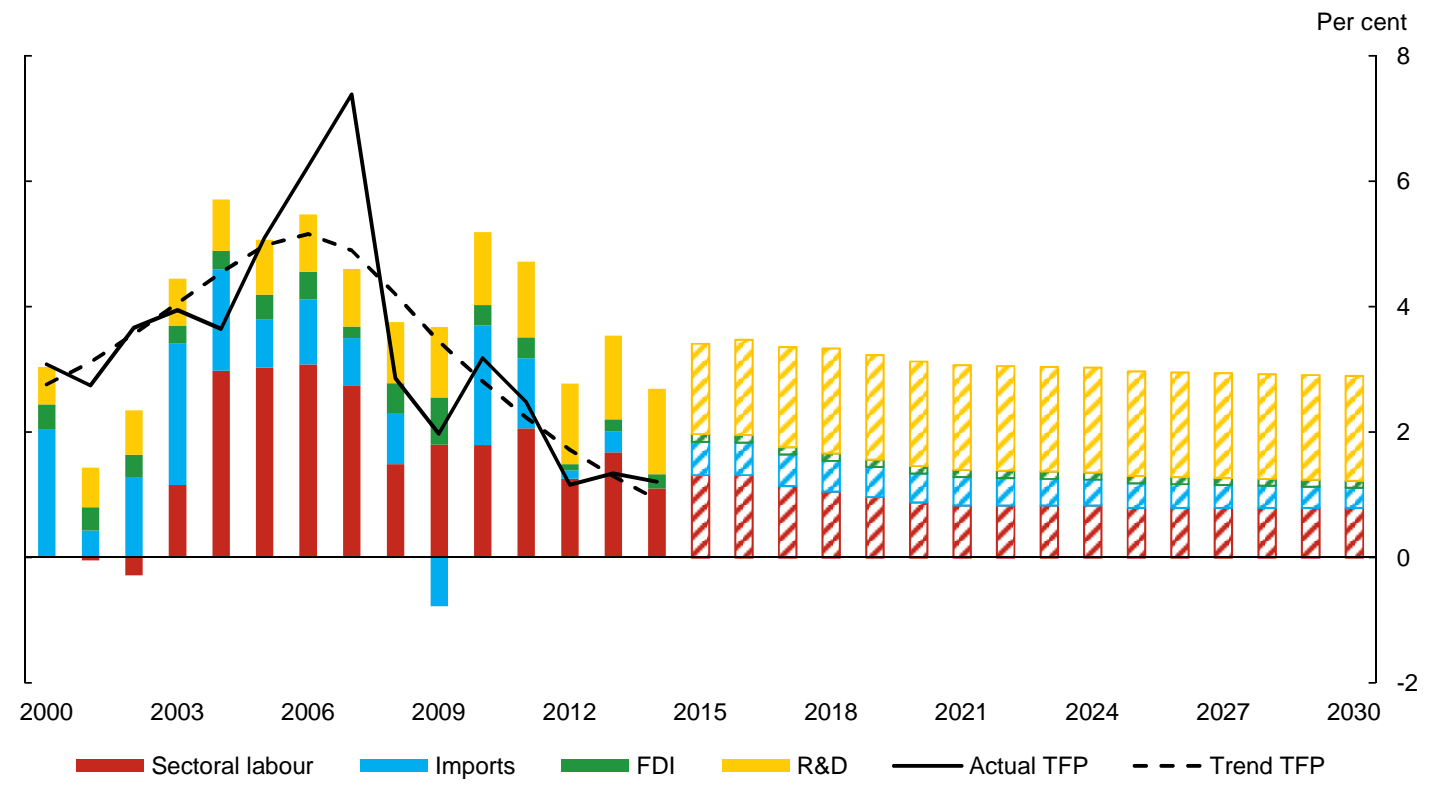

Figure 13: Decomposition of Chinese TFP growth

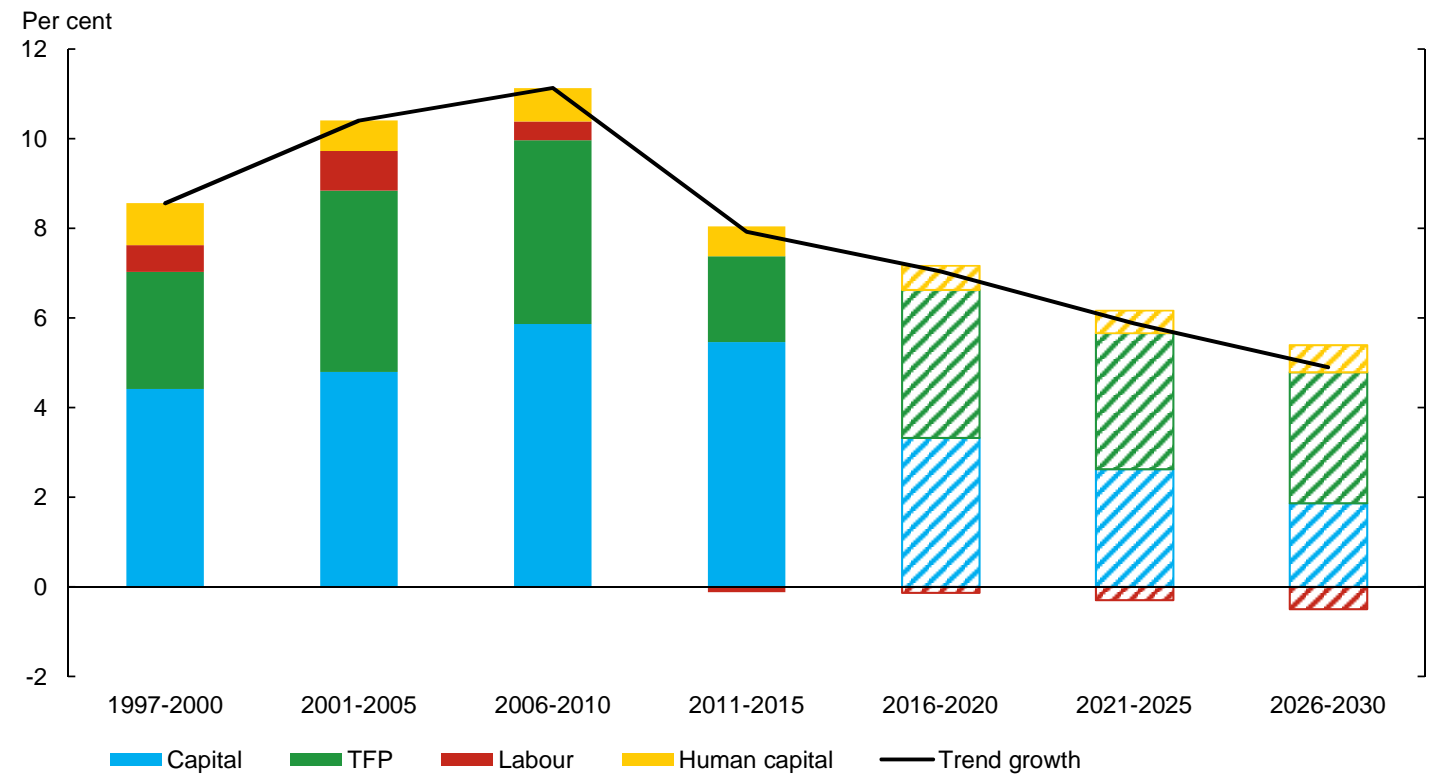

Figure 14: Decomposition of contributions to potential GDP growth 


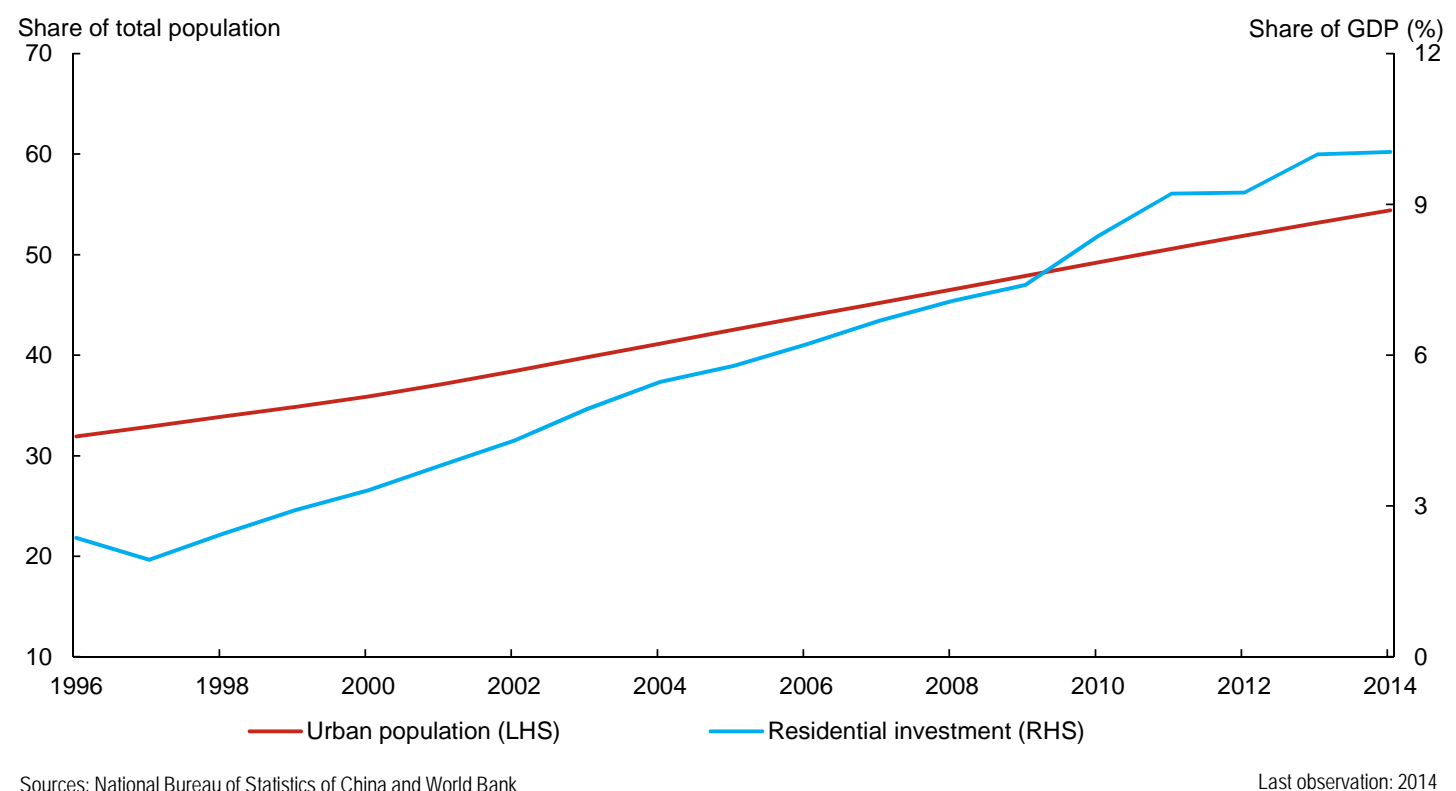

Figure 15: Housing as a share of GDP has risen in China since the mid-1990s

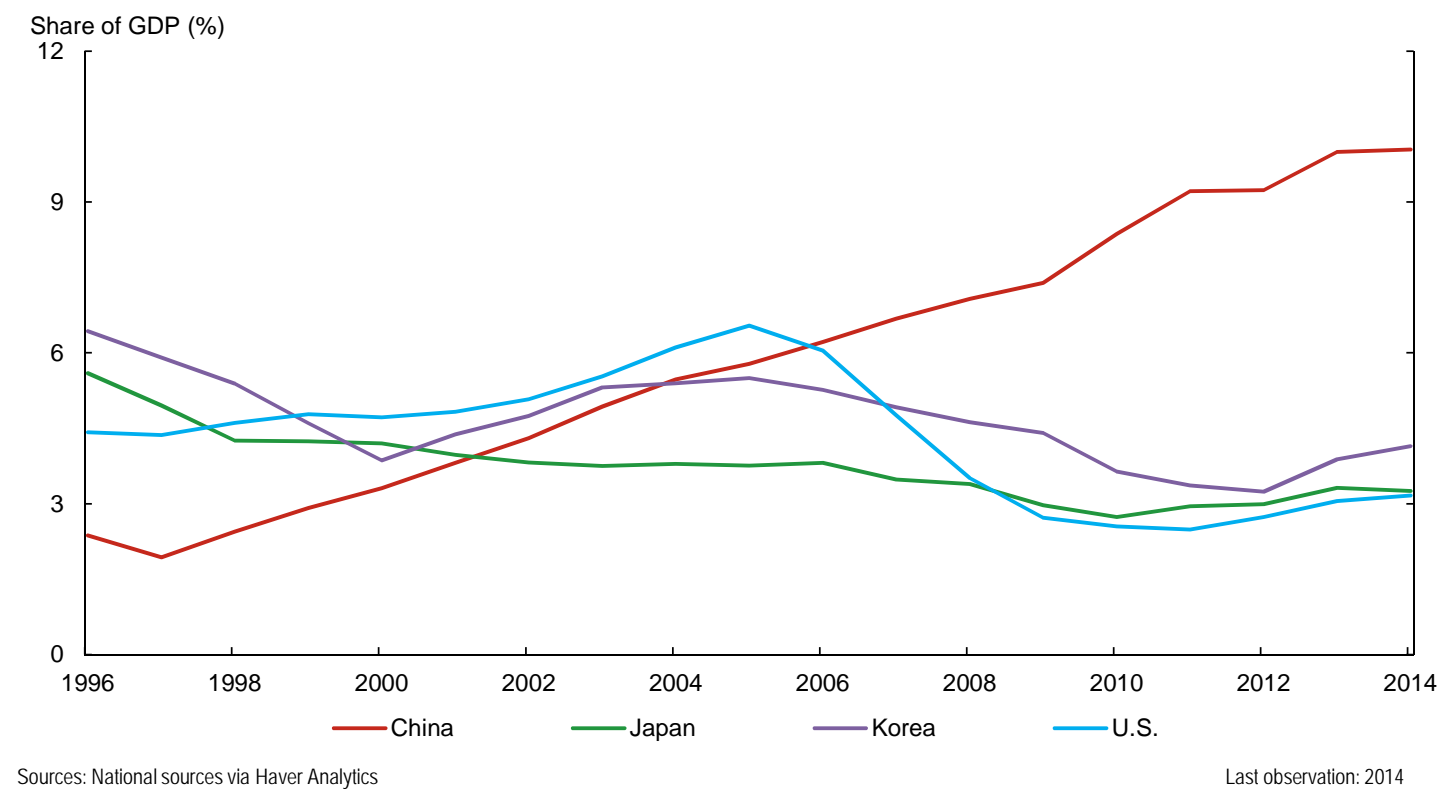

Figure 16: China invests more in housing relative to GDP than other countries 


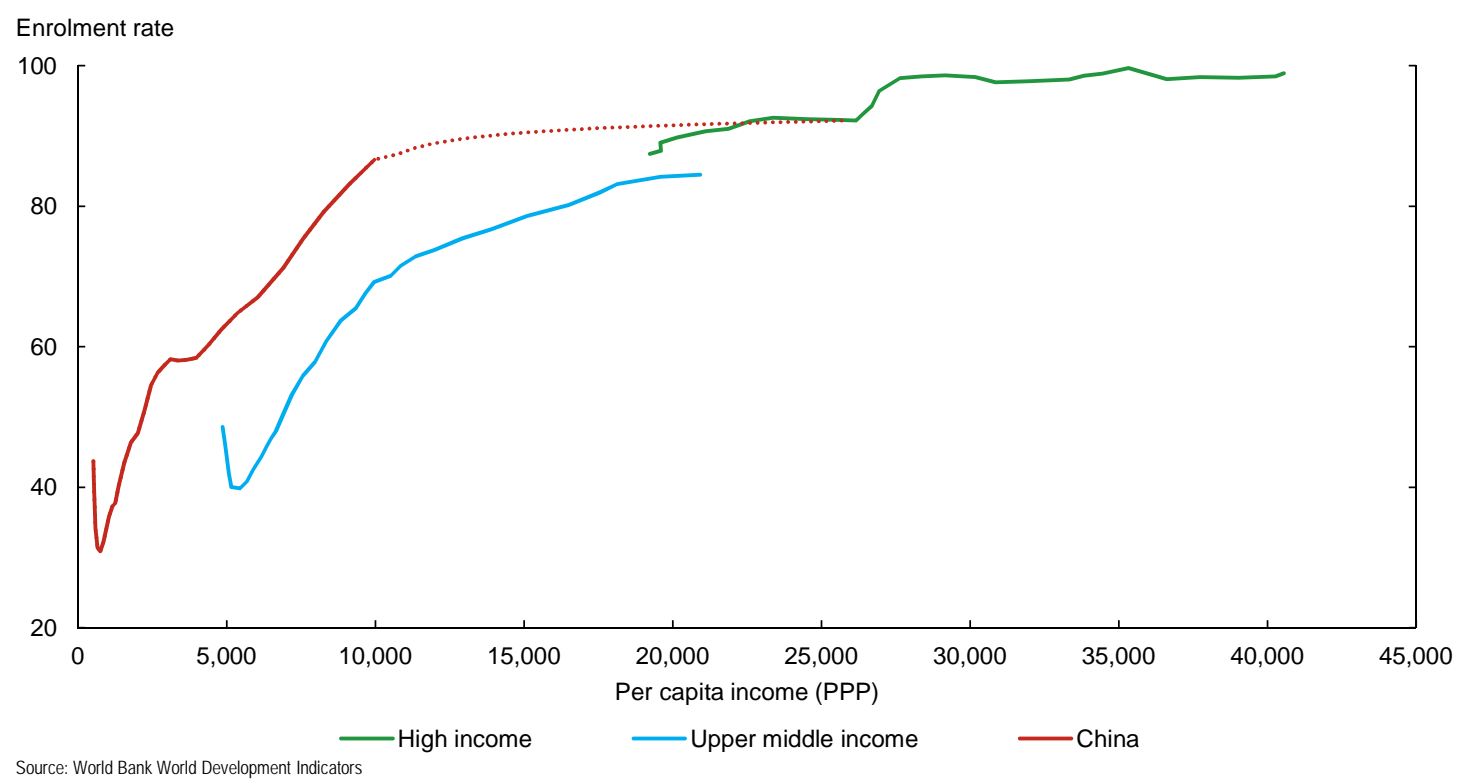

Figure 17: Secondary Enrolment and Per Capita Income: China Relative to Other East Asian Countries

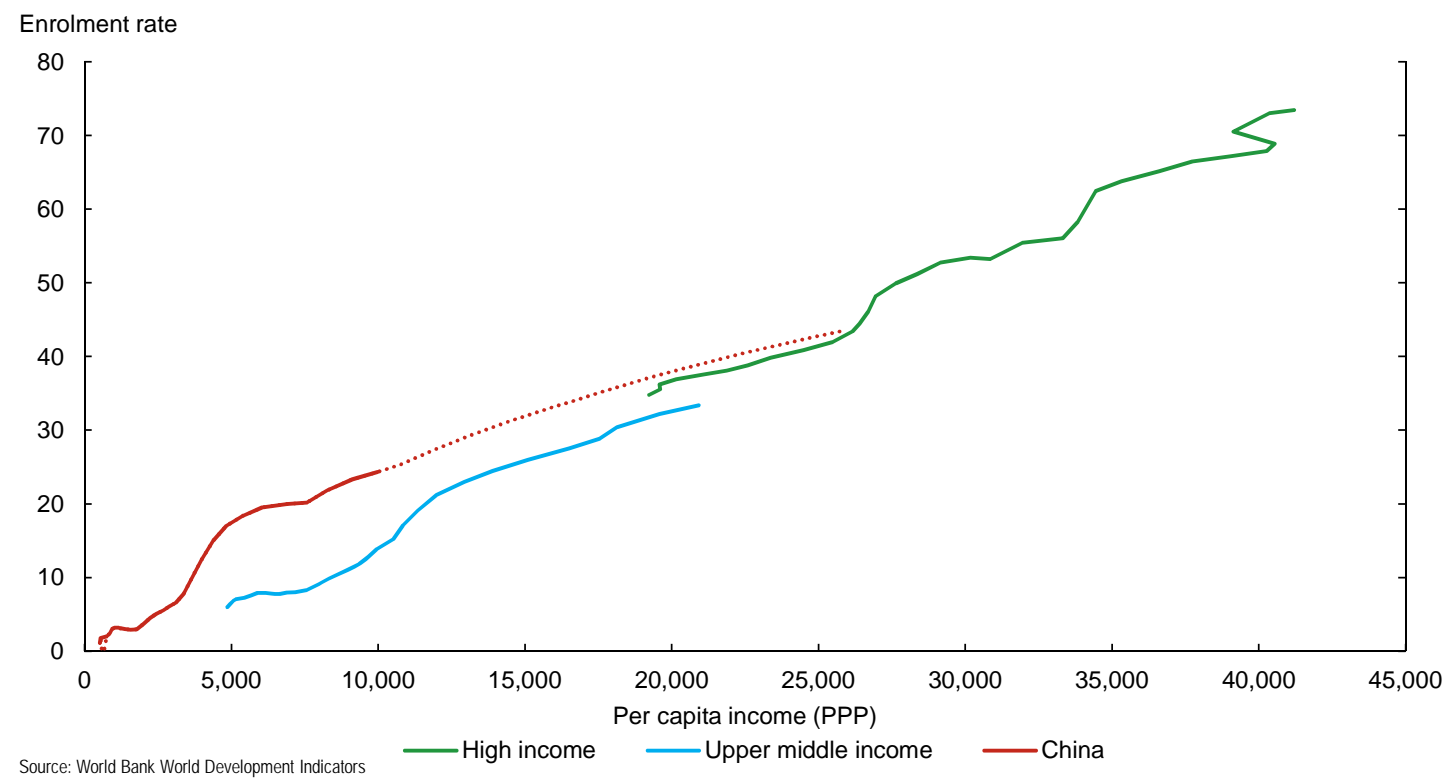

Figure 18: Tertiary Enrolment and Per Capita Income: China Relative to Other East Asian Countries 


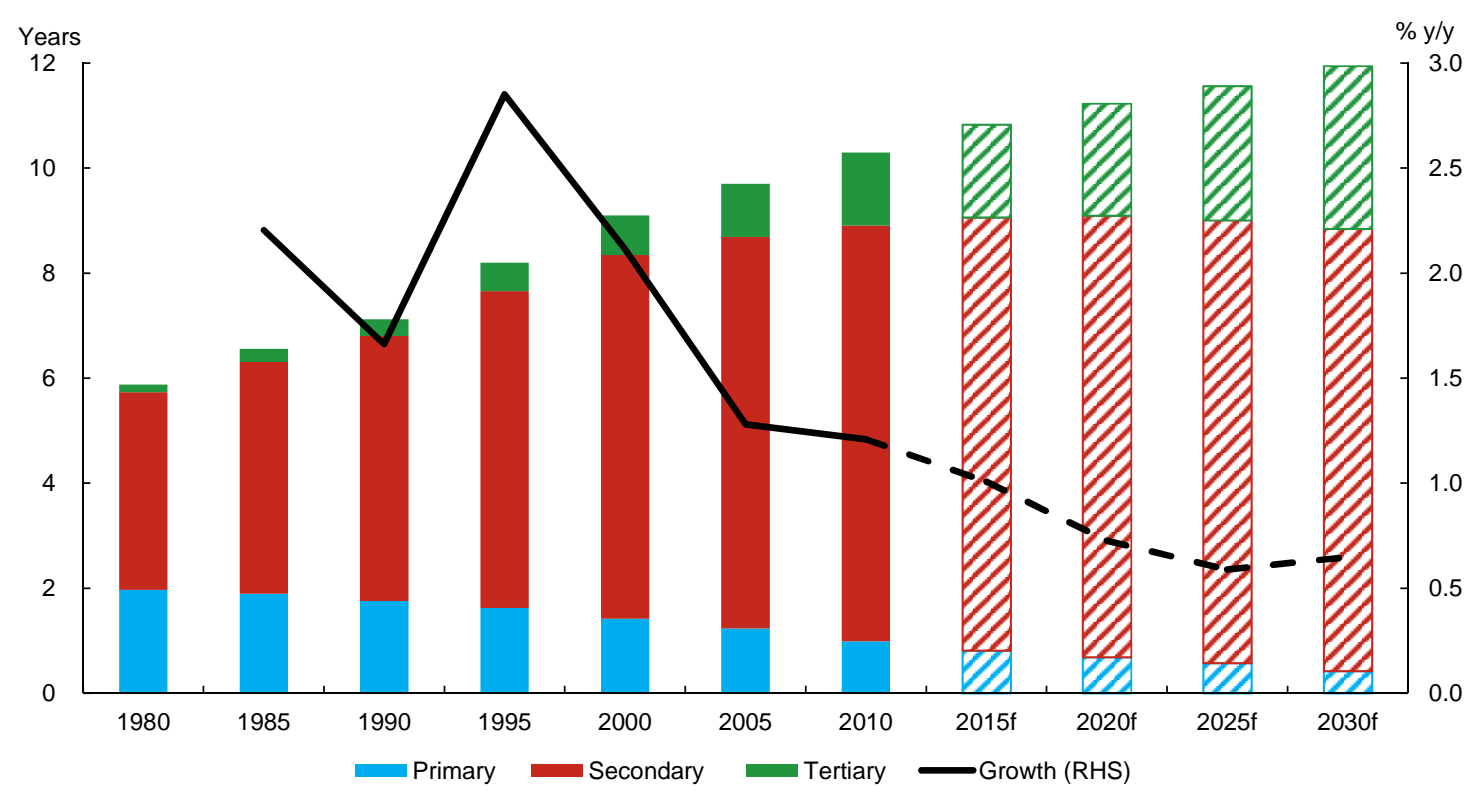

Figure 19: Average Years of Education in China: 1980-2030

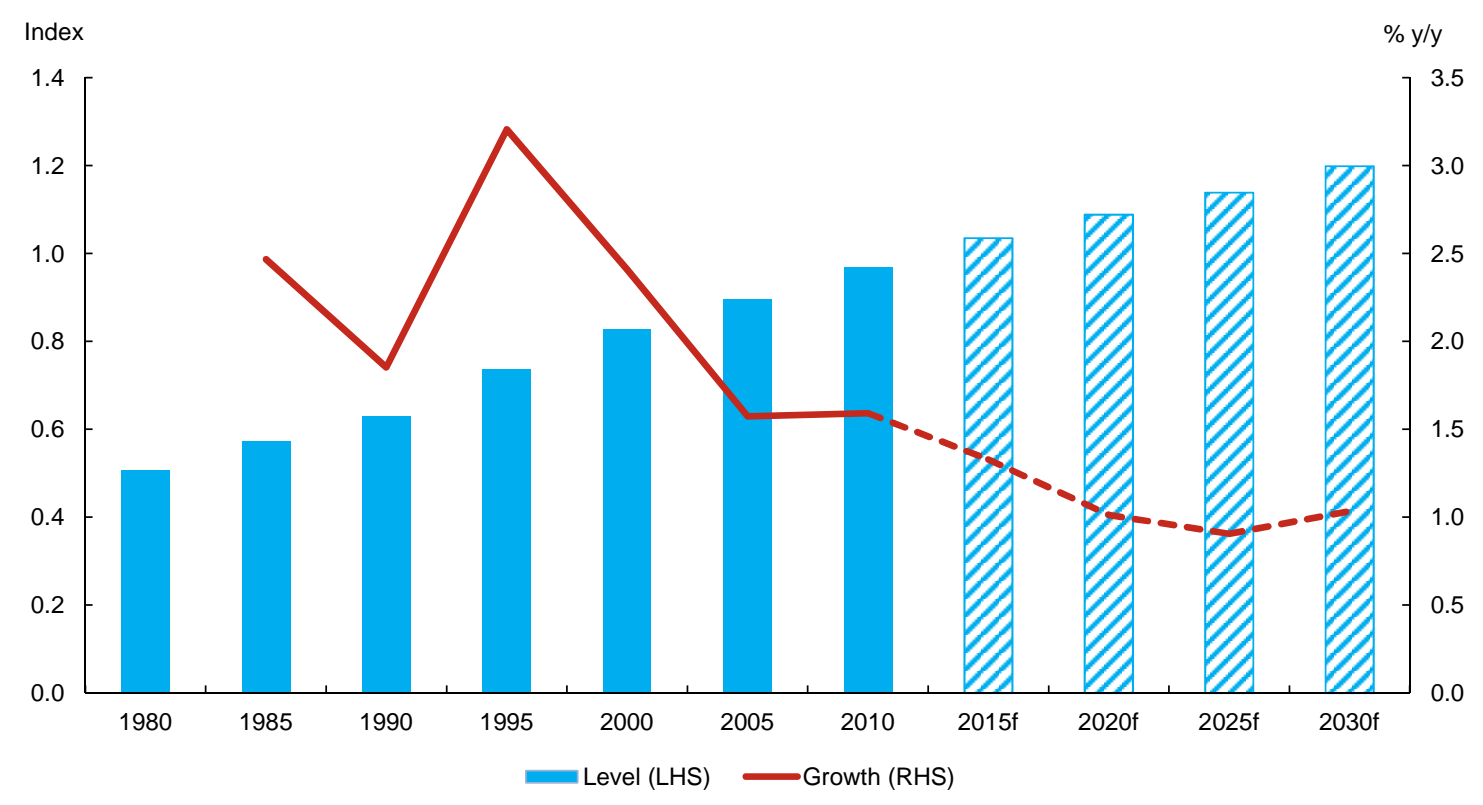

Figure 20: Index of Human Capital: 1980-2030 


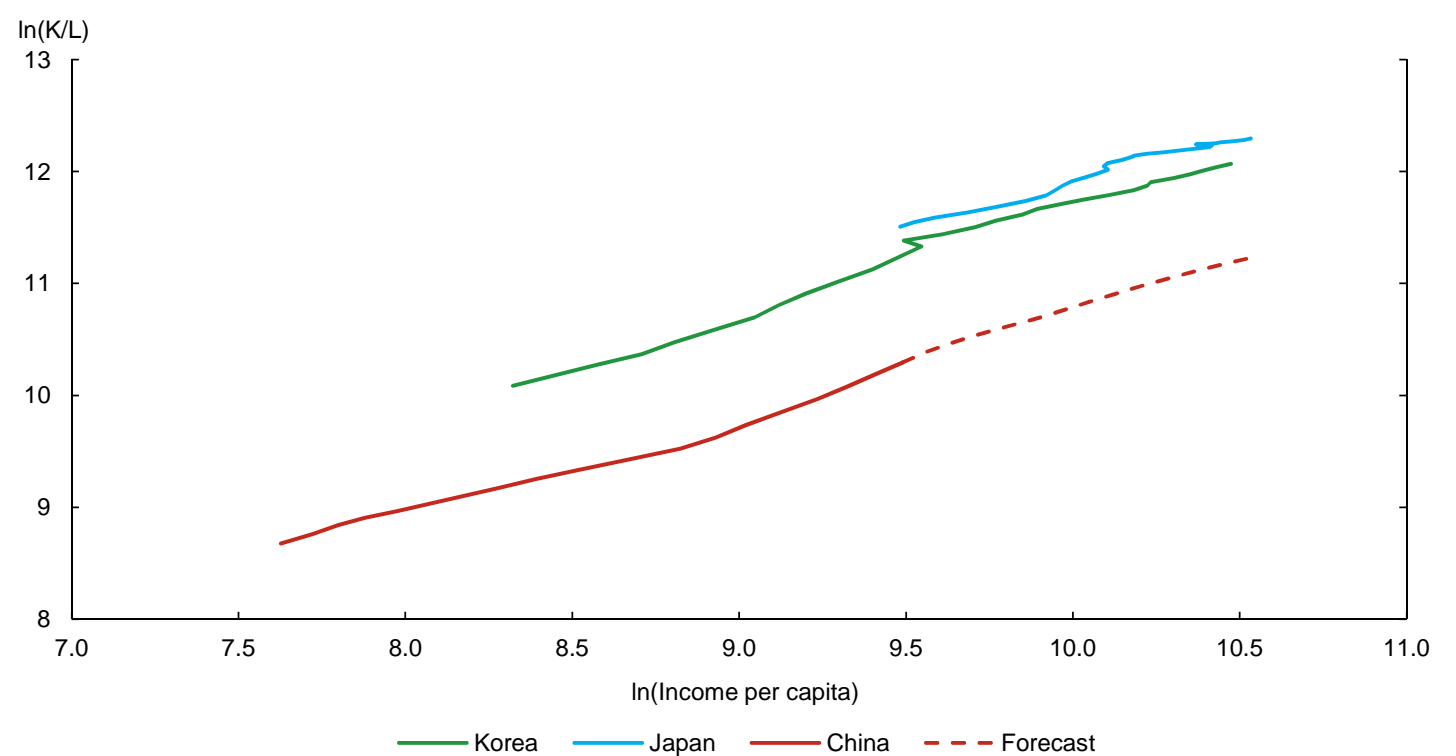

Sources: OECD, IMF, United Nations and authors' calculations

Last observation: 2014

Figure 21: Capital-Labour Ratio and Per Capita Income: China Relative to Other East Asian Countries

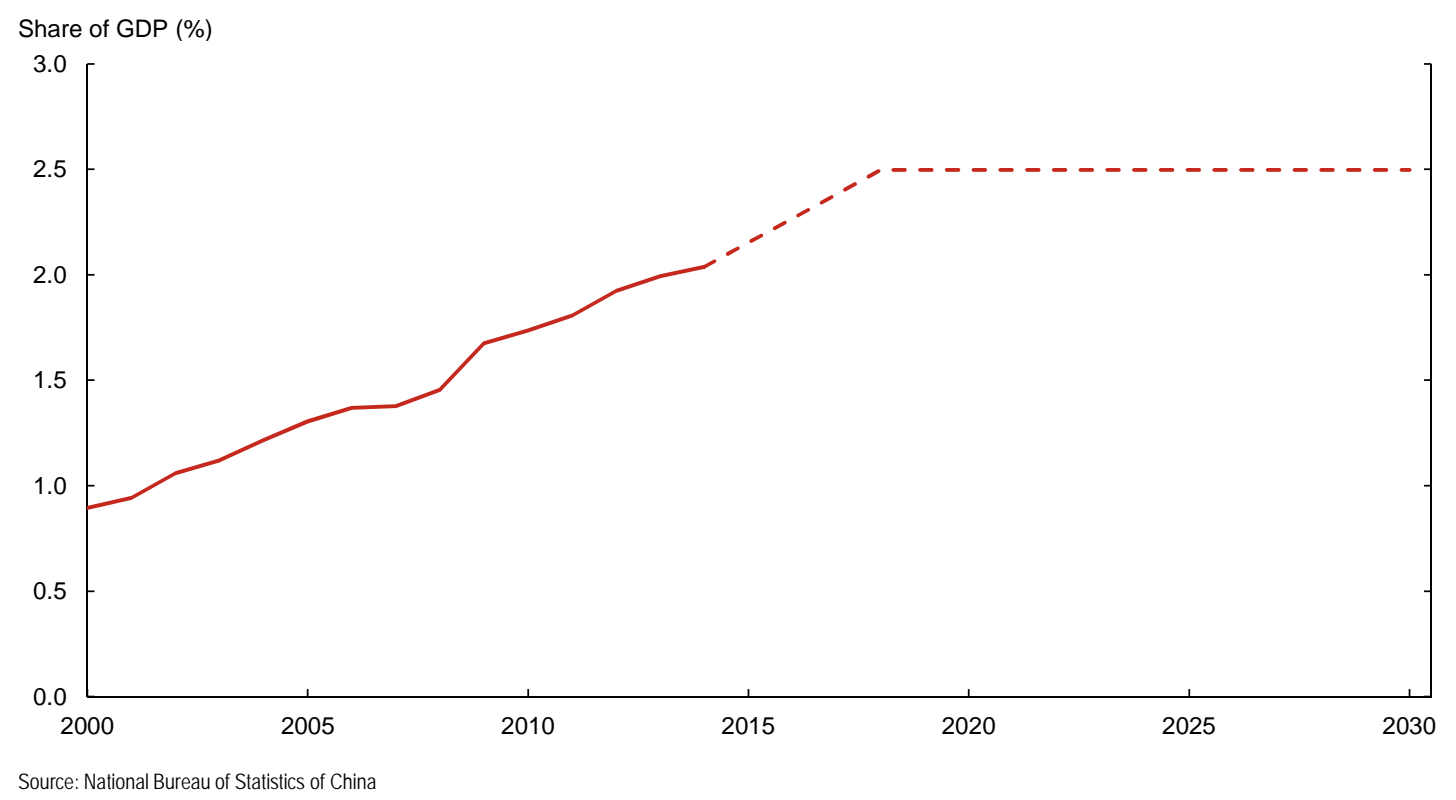

Figure 22: Growth of R\&D Spending as a Share of GDP 


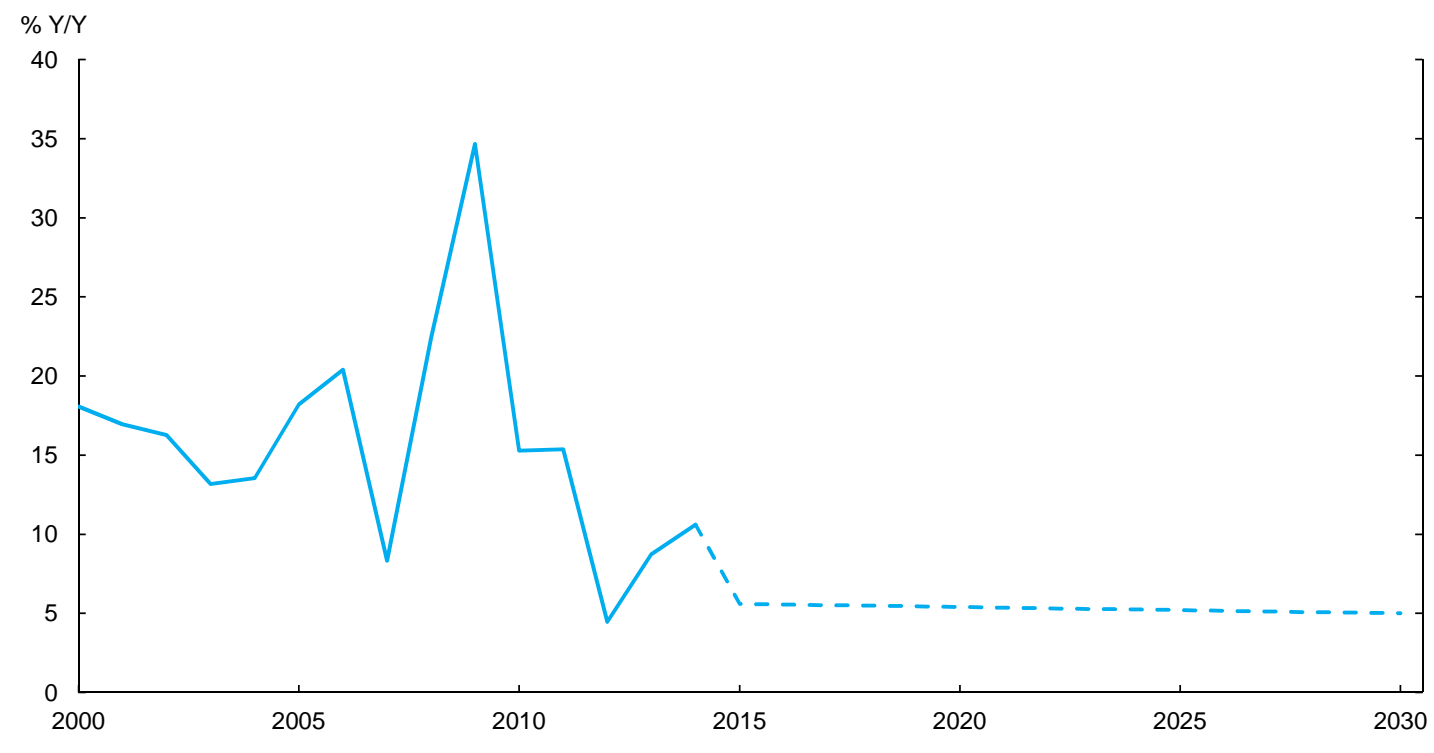

Source: National Bureau of Statistics of China

Figure 23: Growth of Real FDI Stock

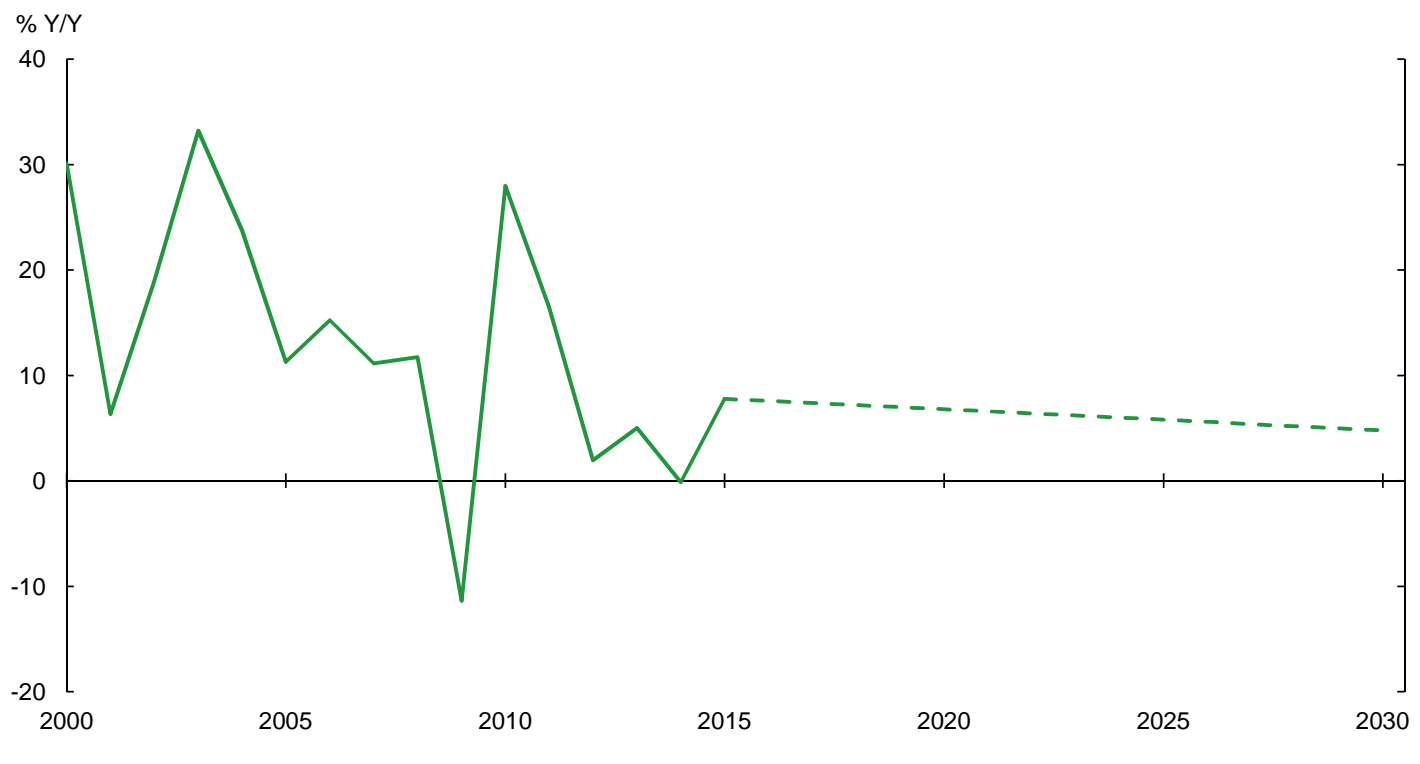

Figure 24: Real Import Growth 


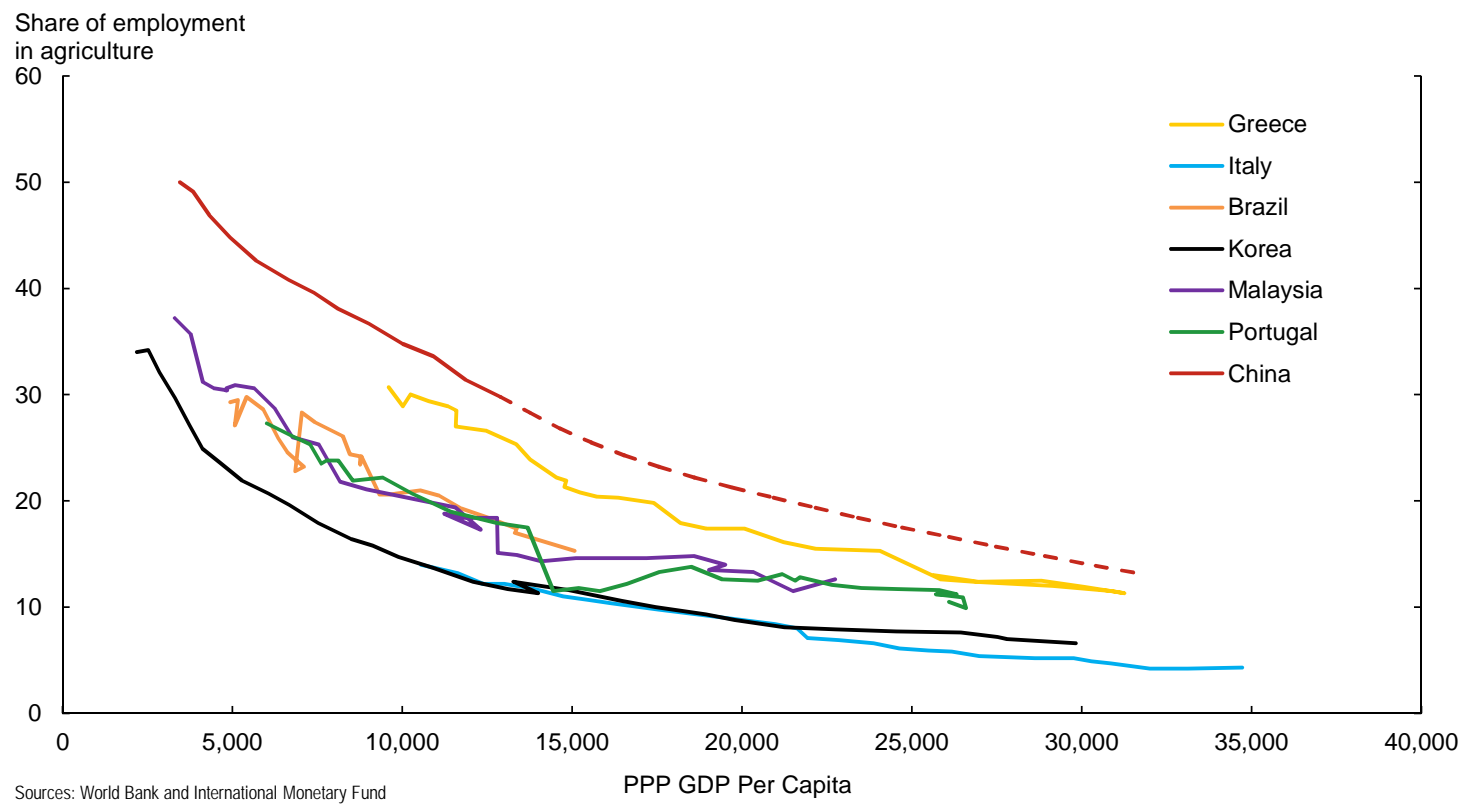

Figure 25: Per Capita GDP and Share of Employment in Agriculture 
Table 1: Depreciation rate of sectors (\%)

\begin{tabular}{cccc}
\hline \hline Construction and installation & Purchase of equipment and instrument & Others & Housing \\
\hline 5 & 15 & 10 & 2 \\
\hline
\end{tabular}

Average depreciation rate (including housing): $\quad 7.0$

Average depreciation rate (excluding housing): 7.6

Note: For more details, see www.worldwide-tax.com/china/chi_reduc.asp

Table 2: Capital Stock Estimates (in 2000 Billion RMB)

\begin{tabular}{cccccc}
\hline \hline Wu & Perkins \& Rawski & Holz $^{*}$ & $\begin{array}{c}\text { Our measure } \\
\text { incl. housing }\end{array}$ & $\begin{array}{c}\text { Our measure } \\
\text { exc. housing }\end{array}$ \\
\hline 1998 & 30.3 & 15.5 & 20.5 & 20.6 & 19.5 \\
\hline 2002 & 44.8 & 22.5 & 29.9 & 28.9 & 26.2 \\
\hline 2005 & 63.2 & 33.3 & & 38.9 & 34.2 \\
\hline
\end{tabular}

Note: Holz computes a number of different series using different rates of depreciation. The one shown here is the one he considers the most reliable.

Table 3: Regression Results for Equation (21)

\begin{tabular}{ccc}
\hline $\begin{array}{c}\text { Measure of credit used } \\
\text { as condition variable }\end{array}$ & Total social financing & $\begin{array}{l}\text { Total social financing excluding } \\
\text { credit used for housing }\end{array}$ \\
\hline$\beta$ & 0.8882 & 0.8670 \\
& $(10.87)$ & $(5.08)$ \\
\hline$\gamma$ & 0.0435 & 0.0315 \\
$(2.87)$ & $(2.99)$ \\
\hline
\end{tabular}

Note: Estimated maximum posterior modes with t-values in parentheses. 
Table 4: Comparison of Estimates of Chinese Trend Growth and Contributing Factors

\begin{tabular}{|cc|c|c|ccccc|ccccc|}
\hline Capital Stock & Period & $\begin{array}{c}\text { GDP } \\
\text { Growth }\end{array}$ & $\begin{array}{c}\text { Trend } \\
\text { Growth }\end{array}$ & \multicolumn{4}{|c|}{ Contribution } & \multicolumn{5}{c|}{ Growth } \\
\hline \multirow{2}{*}{ Measure } & $1997-2000$ & 8.3 & 8.4 & K & L & TFP & HC & K & L & TFP & HC \\
incl. & $2001-2005$ & 9.8 & 10.5 & 4.9 & 0.9 & 4.0 & 0.9 & 8.5 & 1.2 & 2.6 & 1.9 \\
housing & $2006-2010$ & 11.3 & 11.3 & 6.0 & 0.4 & 4.1 & 0.7 & 12.0 & 0.8 & 4.1 & 1.5 \\
& $2011-2015$ & 8.1 & 7.6 & 5.5 & -0.1 & 1.5 & 0.7 & 10.9 & -0.2 & 1.5 & 1.3 \\
& & & & & & & & & & & \\
Measure & $1997-2000$ & 8.3 & 8.5 & 4.4 & 0.6 & 2.6 & 0.9 & 8.7 & 1.2 & 2.6 & 1.9 \\
exc. & $2001-2005$ & 9.8 & 10.4 & 4.8 & 0.9 & 4.0 & 0.7 & 9.6 & 1.8 & 4.0 & 1.4 \\
housing & $2006-2010$ & 11.3 & 11.2 & 5.9 & 0.4 & 4.1 & 0.7 & 11.8 & 0.8 & 4.1 & 1.5 \\
& $2011-2015$ & 8.1 & 7.6 & 5.5 & -0.1 & 1.5 & 0.7 & 11.0 & -0.2 & 1.5 & 1.3 \\
Measure exc. & $1997-2000$ & 8.3 & 8.6 & 4.4 & 0.6 & 2.6 & 0.9 & 8.8 & 1.2 & 2.6 & 1.9 \\
housing and & $2001-2005$ & 9.8 & 10.4 & 4.8 & 0.9 & 4.0 & 0.7 & 9.6 & 1.8 & 4.0 & 1.4 \\
overinvestment & $2006-2010$ & 11.3 & 11.1 & 5.9 & 0.4 & 4.1 & 0.7 & 11.7 & 0.8 & 4.1 & 1.5 \\
& $2011-2015$ & 8.1 & 7.6 & 5.5 & -0.1 & 1.5 & 0.7 & 10.9 & -0.2 & 1.5 & 1.3 \\
\hline
\end{tabular}


Table 5: Cross-Study Comparison of Estimates of Factors Contributing to Chinese GDP Growth in Growth Accounting Exercises

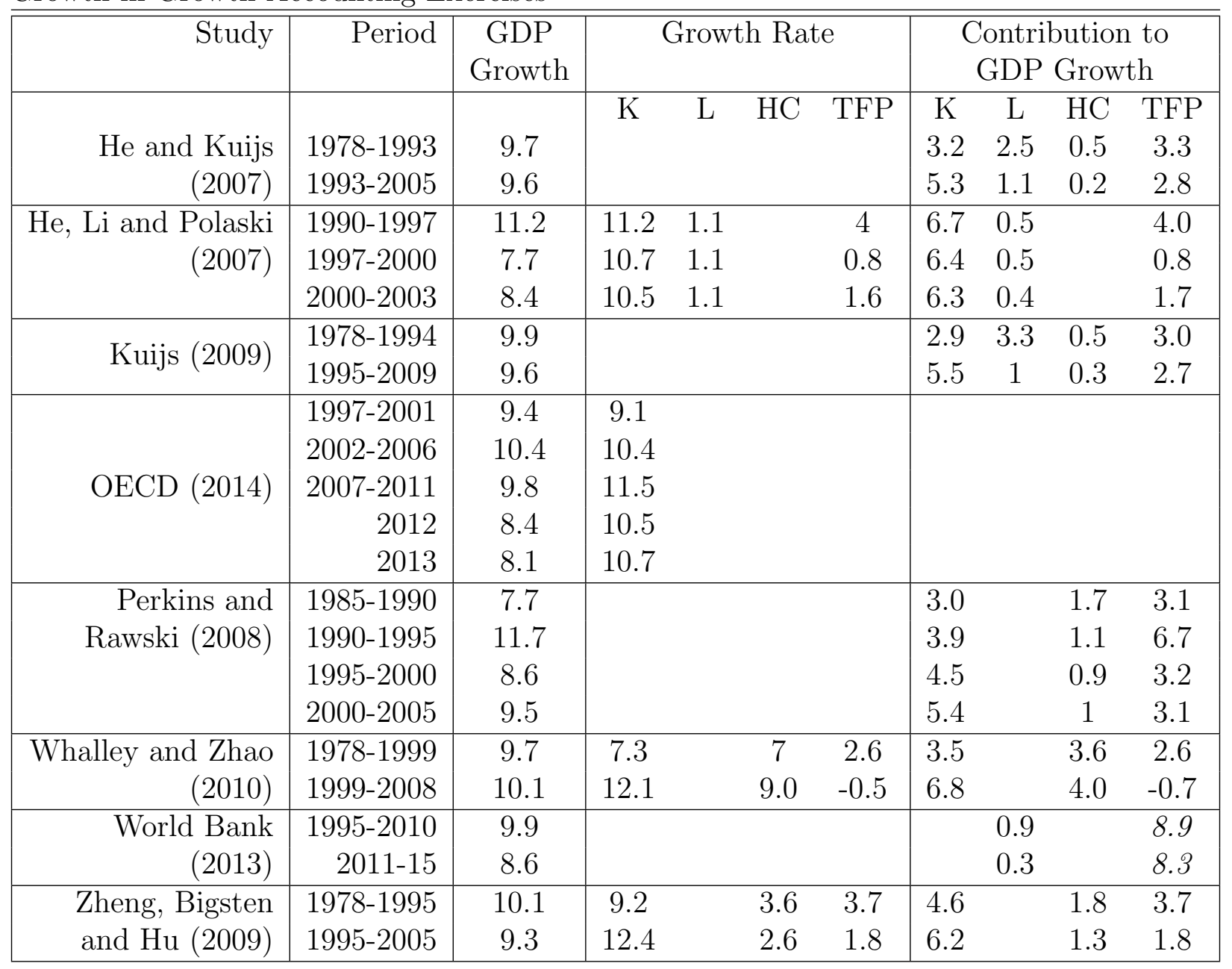

Note: For World Bank (2013), the contribution to GDP growth for labour and labour productivity are shown (and not for TFP growth). 
Table 6: Forecast of Chinese Trend Growth and Contributing Factors

\begin{tabular}{|c|c|c|c|c|c|c|c|c|c|}
\hline$\overline{\text { Period }}$ & $\begin{array}{l}\text { Trend } \\
\text { Growth }\end{array}$ & \multicolumn{4}{|c|}{$\begin{array}{l}\text { Contribution to } \\
\text { Trend Growth }\end{array}$} & \multicolumn{4}{|c|}{ Growth Rate } \\
\hline & & $\mathrm{K}$ & $\mathrm{L}$ & TFP & $\mathrm{HC}$ & $\mathrm{K}$ & $\mathrm{L}$ & $\mathrm{TFP}$ & $\mathrm{HC}$ \\
\hline 2016-2020 & 7.0 & 3.3 & -0.1 & 3.3 & 0.6 & 6.6 & -0.3 & 3.3 & 1.1 \\
\hline $2021-2025$ & 5.9 & 2.6 & -0.3 & 3.0 & 0.5 & 5.3 & -0.6 & 3.0 & 1.0 \\
\hline 2026-2030 & 4.9 & 1.9 & -0.5 & 2.9 & 0.6 & 3.7 & -1.0 & 2.9 & 1.2 \\
\hline
\end{tabular}

Table 7: Cross-Study Comparison of Forecasts of Chinese Trend Growth and Contributing Factors

\begin{tabular}{|rr|r|cccc|}
\hline \hline \multirow{2}{*}{ Study } & \multirow{2}{*}{ Period } & \multirow{2}{*}{ GDP Growth } & \multicolumn{5}{|c|}{ Contribution } \\
& & & to Growth \\
& & & L & HC & TFP \\
\hline Haltmaier (2013) & 2020 & 8.7 & - & -0.2 & - & 8.9 \\
& $2005-2015$ & 8.3 & 5.3 & 0.1 & 0.3 & 2.5 \\
He and & $2015-2025$ & 6.7 & 4.7 & -0.5 & 0.3 & 2.2 \\
& $2025-2035$ & 5.6 & 4.4 & -0.9 & 0.3 & 1.9 \\
Kuijs (2007)* & $2035-2045$ & 4.6 & 3.8 & -1.1 & 0.3 & 1.6 \\
\hline He, Li and & $2011-2015$ & 8.2 & 6.1 & 0.2 & - & 1.9 \\
Polaski (2007) & $2016-2020$ & 7.0 & 5.0 & 0.0 & - & 2.0 \\
\hline Kuijs (2009) & $2010-2015$ & 8.4 & 5.4 & 0.2 & 0.5 & 2.3 \\
& $2016-2020$ & 7.0 & 4.6 & -0.5 & 0.6 & 2.3 \\
\hline & $2014-2018$ & 6.8 & 9.5 & - & - & - \\
OECD(2014) & $2019-2023$ & 4.9 & 6.2 & - & - & - \\
& $2024-2030$ & 3.8 & 4.4 & - & - & - \\
\hline & $2011-2015$ & 8.6 & - & 0.3 & - & 8.3 \\
& $2016-2020$ & 6.9 & - & -0.2 & - & 7.1 \\
& $2021-2025$ & 6.0 & - & -0.2 & - & 6.2 \\
& $2026-2030$ & 5.1 & - & -0.4 & - & 5.5 \\
\hline
\end{tabular}

Notes: (1) The growth rate of K is shown for OECD (2014), and not the contribution to growth. (2) For World Bank (2013), the contribution to GDP growth for labour and labour productivity are shown (and not for TFP growth). 


\section{Appendix B: Data Description}

\author{
Variable \\ Capital stock \\ Capital stock excluding housing
}

Overinvestment adjustment

Credit-to-GDP

Capital-to-Labour

Labour

Human Capital Index

\section{Description/Source}

The total capital stock in each period is calculated using the perpetual inventory method described in Section 2.3. Data source: National Bureau of Statistics of China.

Real residential investment is stripped from real investment to produce the productive capital stock (Section 2.3). Data source: National Bureau of Statistics of China.

The overinvestment adjustment removes excessive investment due to credit expansion from the productive capital stock. This is accounted for by comparing the level of output between an HP filter with $\lambda=1600$ and the PMVF developed by Borio et al. (2013) (Section 2.3.1). Data source: National Bureau of Statistics of China.

Credit-to-GDP is the ratio between total social financing and nominal GDP. Trend credit-to-GDP is computed using an HP filter with $\lambda=40,000$. Data sources: BIS and National Bureau of Statistics of China.

The ratio is forecast using the slope of the capital-to-labour ratio and income per capita of Japan and Korea starting from the base year of 2014. The productive capital stock of Japan and Korea are drawn from the OECD, and the working age population is from the United Nations Population Division. Data sources: OECD, IMF and the United Nations.

Historical and projected growth of the total employed persons and the working age population are drawn from the United Nations Population Division. Working age population is limited to persons between the ages of 15 and 59. Data source: United Nations.

An index of the stock of human capital is computed using methodology outlined in Section 2.2. Data sources: Barro and Lee Educational Attainment Dataset, United Nations. 
Total factor productivity

Research and development

Imports

FDI

Sectoral inputs
Actual TFP is computed as the residual from a Cobb-Douglas production function with $\alpha=0.5$. Trend TFP is computed using an HP filter with $\lambda=40,000$.

$\mathrm{R} \& \mathrm{D}$ is judged to grow to approximately 2.5 per cent of nominal GDP by 2018, and then remain steady to 2030 (Section 3.3). Source for historical data: National Bureau of Statistics of China.

Real imports, deflated by the Chinese GDP deflator, are projected to slow to 5 per cent in 2030. Source for historical data: State Administration of Foreign Exchange.

The real stock of FDI deflated by U.S. CPI is projected to slow to 5 per cent by 2030 (Section 3.3). Source for historical data: National Bureau of Statistics of China.

The contribution of the sectoral distribution of labour to the level of TFP is based on the decline of the agricultural share of employment, with the share in services growing by the same amount (Section 3.3). Data sources: World Bank and IMF. 